Article

\title{
Experimental and Numerical Results of LIFUS5/Mod3 Series E Test on In-Box LOCA Transient for WCLL-BB
}

\author{
Marica Eboli ${ }^{1}$ (D) Francesco Galleni ${ }^{2} \mathbb{D}$, Nicola Forgione ${ }^{2}$, Nicolò Badodi ${ }^{3}\left(\mathbb{D}\right.$, Antonio Cammi $^{3}(\mathbb{D})$ and $^{-}$ \\ Alessandro Del Nevo ${ }^{1, *(1)}$
}

1 Italian National Agency for New Technologies, Energy and Sustainable Economic Development (ENEA), Department of Fusion and Technology for Nuclear Safety and Security, 40032 Camugnano, Italy; marica.eboli@enea.it

2 Department of Civil and Industrial Engineering, University of Pisa, 56122 Pisa, Italy; francescog.galleni@dici.unipi.it (F.G.); nicola.forgione@unipi.it (N.F.)

3 Department of Energy, Politecnico di Milano, 20156 Milano, Italy; nicolo.badodi@polimi.it (N.B.); antonio.cammi@polimi.it (A.C.)

* Correspondence: alessandro.delnevo@enea.it

check for updates

Citation: Eboli, M.; Galleni, F.; Forgione, N.; Badodi, N.; Cammi, A.; Del Nevo, A. Experimental and Numerical Results of LIFUS5/Mod3 Series E Test on In-Box LOCA Transient for WCLL-BB. Energies 2021, 14, 8527. https://doi.org/10.3390/ en14248527

Academic Editors: Christian Veje and Dan Gabriel Cacuci

Received: 27 October 2021

Accepted: 26 November 2021

Published: 17 December 2021

Publisher's Note: MDPI stays neutral with regard to jurisdictional claims in published maps and institutional affiliations.

Copyright: (C) 2021 by the authors. Licensee MDPI, Basel, Switzerland. This article is an open access article distributed under the terms and conditions of the Creative Commons Attribution (CC BY) license (https:/ / creativecommons.org/licenses/by/ $4.0 /)$.

\begin{abstract}
The in-box LOCA (Loss of Coolant Accident) represents a major safety concern to be addressed in the design of the WCLL-BB (water-cooled lead-lithium breeding blanket). Research activities are ongoing to master the phenomena and processes that occur during the postulated accident, to enhance the predictive capability and reliability of numerical tools, and to validate computer models, codes, and procedures for their applications. Following these objectives, ENEA designed and built the new separate effects test facility LIFUS5/Mod3. Two experimental campaigns (Series D and Series E) were executed by injecting water at high pressure into a pool of PbLi in WCLL-BB-relevant parameter ranges. The obtained experimental data were used to check the capabilities of the RELAP5 system code to reproduce the pressure transient of a water system, to validate the chemical model of $\mathrm{PbLi}$ /water reactions implemented in the modified version of SIMMER codes for fusion application, to investigate the dynamic effects of energy release on the structures, and to provide relevant feedback for the follow-up experimental campaigns. This work presents the experimental data and the numerical simulations of Test E4.1. The results of the test are presented and critically discussed. The code simulations highlight that SIMMER code is able to reproduce the phenomena connected to $\mathrm{PbLi} /$ water interaction, and the relevant test parameters are in agreement with the acquired experimental signals. Moreover, the results obtained by the first approach to SIMMER-RELAP5 code-coupling demonstrate its capability of and strength for predicting the transient scenario in complex geometries, considering multiple physical phenomena and minimizing the computational cost.
\end{abstract}

Keywords: SIMMER code; RELAP5 code; in-box LOCA; WCLL breeding blanket; LIFUS5/Mod3

\section{Introduction}

In the framework of the development of the European DEMO nuclear fusion reactor, Water Cooled Lithium Lead (WCLL) BB is considered a candidate option for the leading breeding blanket technology [1-4], and has been recently considered in the ITER Test Blanket Module (TBM) program [5]. The major safety issue for the design of this component is the interaction between $\mathrm{PbLi}$ and water caused by a tube rupture in the breeding zone, the so-called in-box LOCA (Loss of Coolant Accident) scenario. This phenomenon has been investigated in order to obtain robust data for the validation of system code used in deterministic safety analyses. Indeed, a qualified code is of primary importance for the evaluation of the accidental consequences and for choosing possible mitigating countermeasures, besides proposing design solutions to prevent damages to the blanket box structures. 
The $\mathrm{R} \& \mathrm{D}$ related to the $\mathrm{PbLi} /$ water interaction took several aspects into account. The first was the implementation of the $\mathrm{PbLi}$ / water chemical reaction model in SIMMER code [6], so the verification and validation activity required the application of a standard code methodology [7-9] to experimental data with reproducible and defined initial and boundary conditions [10,11] provided by the new LIFUS5/Mod3 campaigns [12]. The facility was commissioned and two separate effects test (SET) campaigns were executed: the first one (Series D) had the main objective of the generation of an experimental database for the validation of the chemical model in the modified version SIMMER codes; the second one (Series E) focused on the investigations of interaction phenomena between $\mathrm{PbLi}$ and water, which strictly depends on choked flow instauration and pressure difference as well as the thermo-hydraulic conditions of the injected water [13]. Meanwhile, numerical simulation activities were performed [14-16]. The numerical results were compared with the experimental data, pointing out differences and similarities to analyze capabilities and limits of the SIMMER codes. The comparison was made by qualitative and quantitative accuracy evaluations; the former was based on the identification of phenomenological windows and of the relevant thermo-hydraulic aspects, and the latter was based on a systematic analysis of the deviation of the predicted target variables with respect to the corresponding measured values.

Experimental results also constituted a useful database for the support of a new STH/2D coupling calculation tool (STH—System Thermal Hydraulics codes) $[17,18]$. The strength of this tool is the possibility of obtaining high-fidelity calculations in complex geometries, considering multiple physical phenomena and minimizing the computational cost. Its development permitted the performance of a preliminary analysis on WCLL TBM and its ancillary systems, investigating the behavior under an in-box LOCA postulated event $[19,20]$. The developed coupling technique can be defined as a "two-way", "nonoverlapping", "online" methodology [21], with the SIMMER and RELAP5 computational domains separated by interfaces and linked by an external script. Through these interfaces, data are exchanged at each time-step between the two codes in both directions in order to provide proper boundary conditions for the advancement of the calculations. The synchronized advancement in the time domain is controlled by means of an implicit coupling methodology [21].

The present work gives a complete and comprehensive analysis of the experimental results of Test E4.1 and the numerical simulations performed both with SIMMER-III standalone, and with the SIMMER-III and RELAP5/Mod3.3 coupling tools. The results are critically discussed, highlighting the shortcomings and potential of the experimental procedures as well as the deficiencies and capabilities of the numerical tools.

\section{Materials and Methods: LIFUS5/Mod3 Facility}

LIFUS5/Mod3 (Figure 1) is a separate effects test facility, designed and constructed at ENEA CR Brasimone [12]. Its core is composed of two reaction vessels, S1A and S1B, designed to perform experiments over a wide variety of liquid metals, such as eutectic lead-lithium, eutectic lead-bismuth, and pure lead. Each vessel of the facility has a different functionality: S1A has a geometrical capacity of $100 \mathrm{~L}$ and was recently used to characterize the leak detection systems in LBE pool [22], whereas the vessel S1B is smaller, with a geometrical capacity of $30 \mathrm{~L}$. This latter vessel was employed to study the PbLi-water interaction, in the framework of the EUROfusion program, with a main objective of investigating the phenomena occurring during the interaction between the two fluids. The data collected are used mainly to validate the chemical model implemented in the SIMMER code, together with the following expected outcomes:

- the generation of detailed and reliable experimental data;

- the investigation of the dynamic effects of energy release, chemical reaction, and hydrogen production on the structures;

- the broadening of the current knowledge of physicochemical behavior of PbLi eutectic alloys, and the understanding of relevant phenomena associated with its use; 
- the expansion of the database used for code verification.

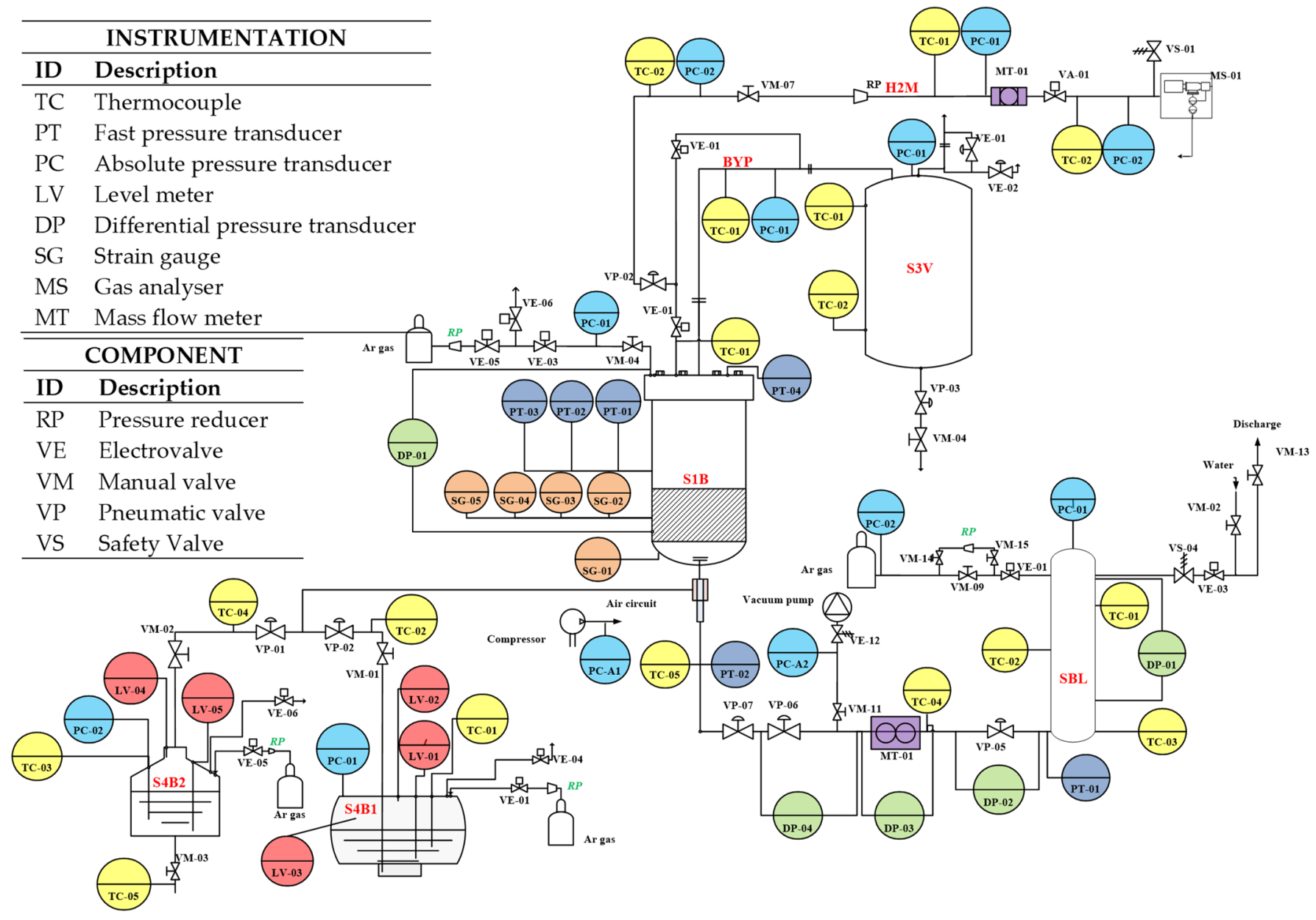

Figure 1. LIFUS5/Mod3 Process and Instrumentation diagram.

\subsection{Facility Description}

LIFUS5/Mod3 was built by upgrading the previously existing LIFUS5/Mod2 facility [23]. The new experimental plant maintains the expansion vessel (S3V) and the old reaction vessel (S1A), while installing a new vessel, namely, S1B. This new vessel holds a smaller volume than S1A but can withstand higher pressures of up to 200 bar at a temperature of $500{ }^{\circ} \mathrm{C}$, being representative of the WCLL operative conditions, and in accordance with PED directives [24]. The expansion vessel S3V is shared between the old and new branches and is used to collect gasses or other substances released by the test sections in case of rupture disk activation. The facility is composed of five main components (see Table 1):

- $\quad$ The main reaction vessel, $\mathrm{S1B}$, where the water-PbLi interaction takes place;

- The water tank SBL and the injection line, which is used to bring water to test conditions. This is built out of an enlarged section of pipe, connected by a line to the bottom of S1B; pressure is maintained inside this tank by the action of an argon cylinder connected to its top;

- The safety expansion vessel, S3V, connected to S1B by means of two in-series rupture disks, to avoid damaging the rest of the facility in case of overpressure;

- The PbLi storage tanks, S4B1 and S4B2, holding, respectively, fresh and exploited alloys;

- The hydrogen extraction and analysis system. 
Table 1. LIFUS5/Mod3 component design features.

\begin{tabular}{ccc}
\hline Component & Parameter & Value \\
\hline \multirow{3}{*}{ S1B reaction vessel } & Volume $(\mathrm{L})$ & 30 \\
& Inner diameter $(\mathrm{m})$ & 0.28 \\
& Height $(\mathrm{m})$ & 0.56 \\
& Design pressure (bar) & 200 \\
& Design temperature $\left({ }^{\circ} \mathrm{C}\right)$ & 500 \\
\hline \multirow{3}{*}{ SBL water pipe } & Volume $(\mathrm{L})$ & 4.05 \\
& Inner diameter $(\mathrm{m})$ & 0.04 \\
& Design pressure $($ bar $)$ & 200 \\
& Design temperature $\left({ }^{\circ} \mathrm{C}\right)$ & 350 \\
\hline \multirow{3}{*}{ S3V dump vessel } & Volume $(\mathrm{L})$ & 2000 \\
& Inner diameter $(\mathrm{m})$ & 1 \\
& Design pressure $(\mathrm{bar})$ & 10 \\
& Design temperature $\left({ }^{\circ} \mathrm{C}\right)$ & 400 \\
\hline \multirow{2}{*}{ S4B1 fresh PbLi } & Volume $(\mathrm{L})$ & 400 \\
& Inner diameter $(\mathrm{m})$ & 0.54 \\
& Length $(\mathrm{m})$ & 1.56 \\
& Design temperature $\left({ }^{\circ} \mathrm{C}\right)$ & 450 \\
\hline S4B2 depleted $\mathrm{PbLi}$ & Volume $(\mathrm{L})$ & 400 \\
& Inner diameter $(\mathrm{m})$ & 0.54 \\
& Length $(\mathrm{m})$ & 1.56 \\
& Design temperature $\left({ }^{\circ} \mathrm{C}\right)$ & 450 \\
\hline
\end{tabular}

Each of these components is equipped with instrumentation to allow for the acquisition of temperature and pressure data and is heated by means of a heat tracing system surrounded by mineral wool.

\subsubsection{Reaction Vessel S1B}

The main vessel, $\mathrm{S} 1 \mathrm{~B}$, has an internal volume of about $30 \mathrm{~L}$, and during each test, it is filled with $25 \mathrm{~L}$ of PbLi. It is completely isolated from the external environment by a top flange, and the remaining internal volume is filled with argon cover gas to avoid a $\mathrm{PbLi}$ reaction with moisture and oxygen in the air. The internal geometry of the vessel is composed of a cylinder with a radius of $0.1285 \mathrm{~m}$, and a lower spherical portion with the same radius; the overall height of this vessel is $0.555 \mathrm{~m}$. S1B is connected to the rest of the facility components by a series of penetrations in its top flange, that are shown in the $\mathrm{P}$ and ID of Figure 1, and which are:

- A gooseneck seal to allow thermocouples cables passage;

- The housing for the fast pressure transducer;

- The hydrogen extraction line connection;

- The expansion line connecting the vessel to S3V via the rupture disks;

- The housing of a differential pressure meter for level-monitoring and a pressure transducer for absolute pressure-measurement.

Other penetrations are needed on the sides and on the bottom of the vessel to allow extensive data collection; in particular, three more penetrations, at a $120^{\circ}$ angle from each other, are made on the walls of the vessel (Figure 2a). These house the fast pressure transducers (PT) for the acquisition of the pressure-wave propagation.

A 2" penetration is placed at the bottom of the vessel to allow for the loading and unloading of the $\mathrm{PbLi}$ alloy, and it also acts as the terminal part of the water injection line. A complete list of the penetrations and instrumentations mounted on the vessel S1B is shown in Table 2. 


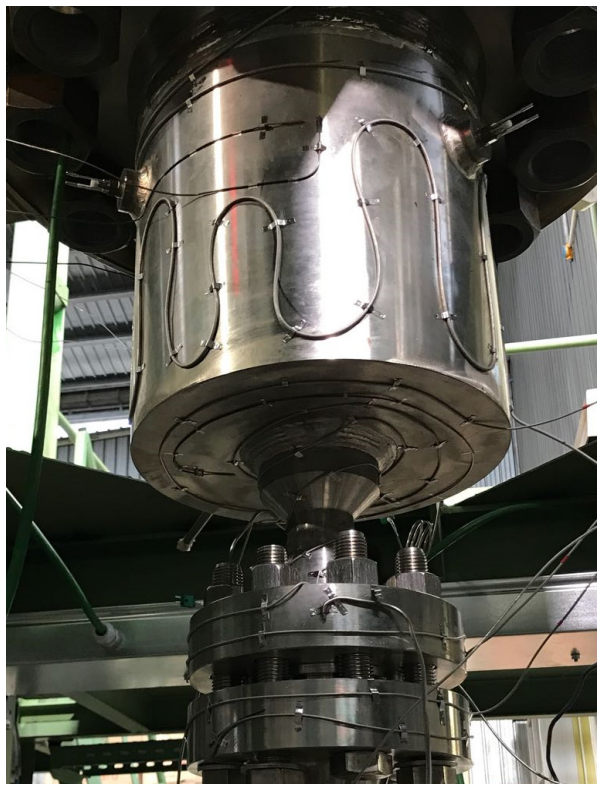

(a)

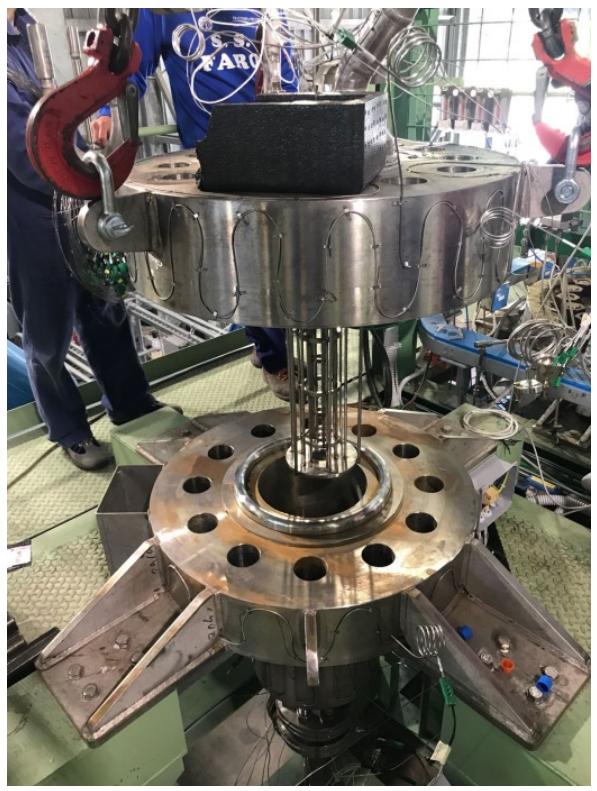

(b)

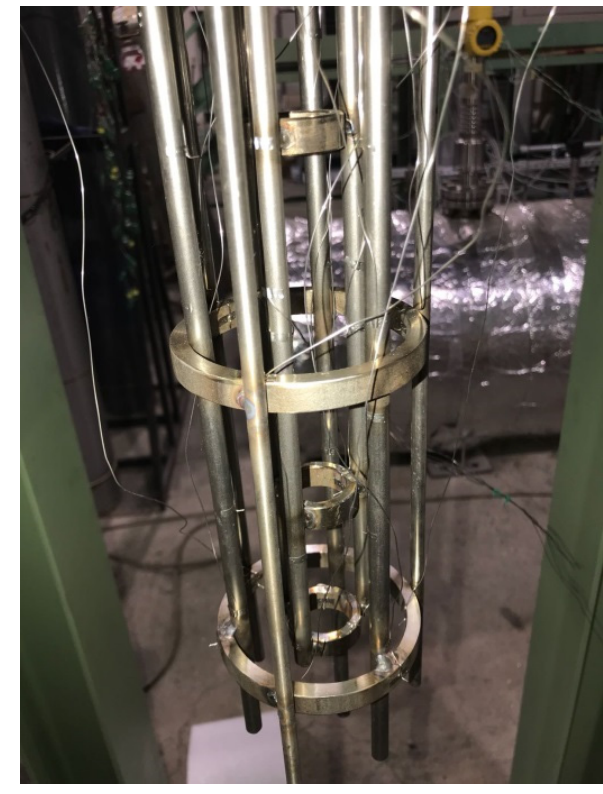

(c)

Figure 2. LIFUS5/Mod3 test section. (a) External surface of vessel S1B; (b) assembly of the test section; (c) test section and thermocouples detail.

Table 2. Summary of the penetrations and instrumentation installed on the vessel S1B.

\begin{tabular}{cccc}
\hline Position & $\mathbf{N}^{\circ}$ & Utilization & Component ID \\
\hline A & 1 & Water injection and PbLi & Sharging/discharging system \\
B & 1 & Connection to S3V-expansion/dump vessel & Steel pipe \\
C & 1 & Gooseneck sealing system to TC passage & Test section TCs \\
D & 1 & Hydrogen measurement system & MS-H2M-01 \\
E & 1 & DP meter and PC pressure transducer & DP-S1B-01 \\
F & 1 & PT fast pressure transducer & PC-S1B-01 \\
G-H-I & 3 & PT on cylindrical shell & PT-S1B-04 \\
L & 1 & DP meter & PT-S1B-01/02/03 \\
On shell & 3 & Strain gages (circumferential) & SG-S1B-02/03/04 \\
On shell & 1 & Strain gages (axial) & SG-S1B-05 \\
On bottom & 1 & Strain gages (radial) & SG-S1B-01 \\
\hline
\end{tabular}

\subsubsection{Test Section}

Figures 2 and 3 show the test section inserted into the vessel S1B. This component is welded directly on the top flange of S1B and is designed to be axial-symmetric. The upper holed plate, visible on the left part of Figure 3a, delimits the interaction zone where the chemical reaction can take place, by breaking down the impinging jet of subcooled water from the injector. Simultaneously, the holes allow for the passage of water vapor and hydrogen produced during the tests.

The lateral sides of the test section are, instead, open, to allow for the propagation of the pressure wave generated during the interaction and its measurement through the sensors positioned on the sides of the vessel. These sensors include both strain gages and dynamic pressure transducers to record the vessel deformation and pressure-wave intensity and shape. A total of $740.5 \mathrm{~mm}$ K-type thermocouples are installed on the test section over six different levels ranging in elevation from the injector to the holed plate, and uniformly distributed in radial directions (Figure 2c). By means of this configuration, the map of the temperature can be identified as well as the layout of the water jet (symmetry, width, and height). The exact positioning of the thermocouples is shown in Figure $3 \mathrm{~b}$. 


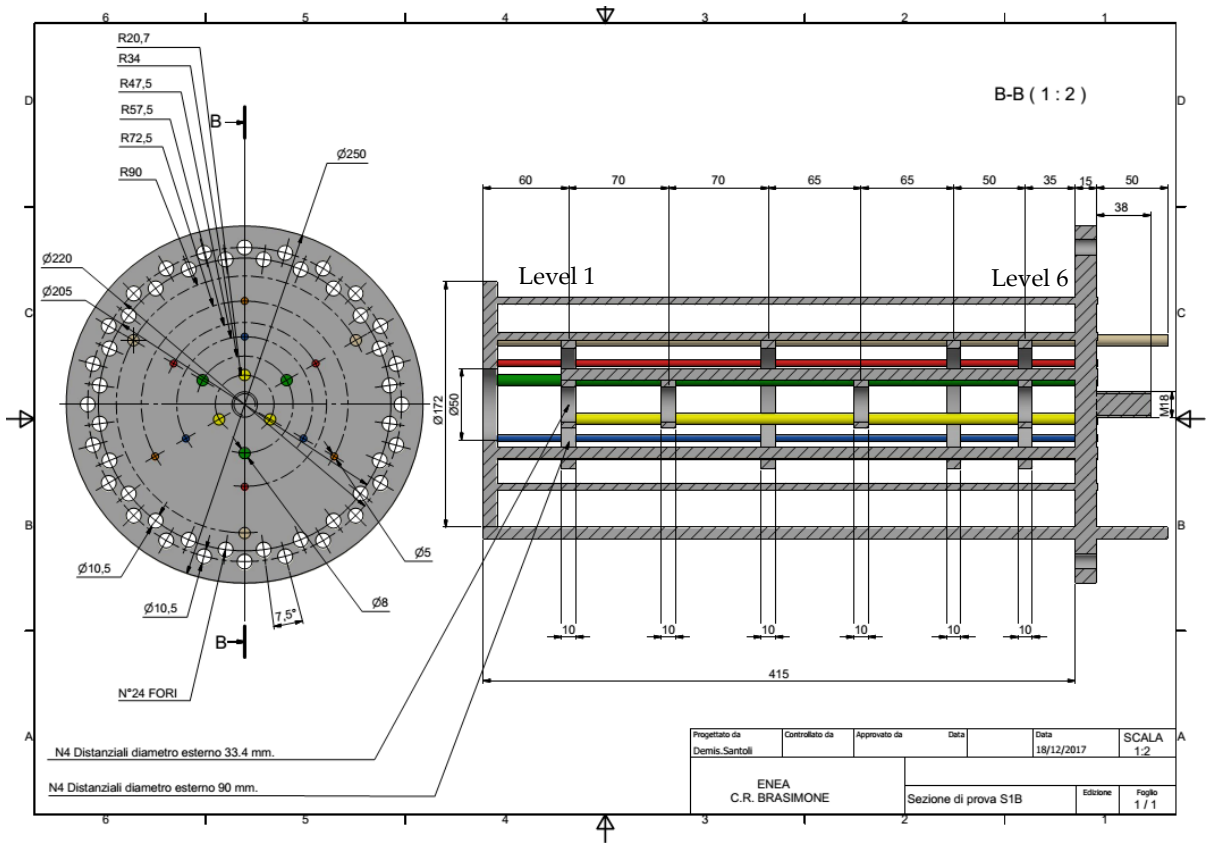

(a)
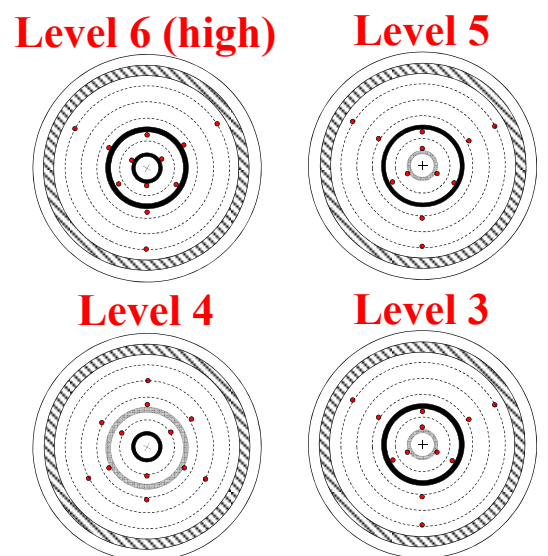

Level 2
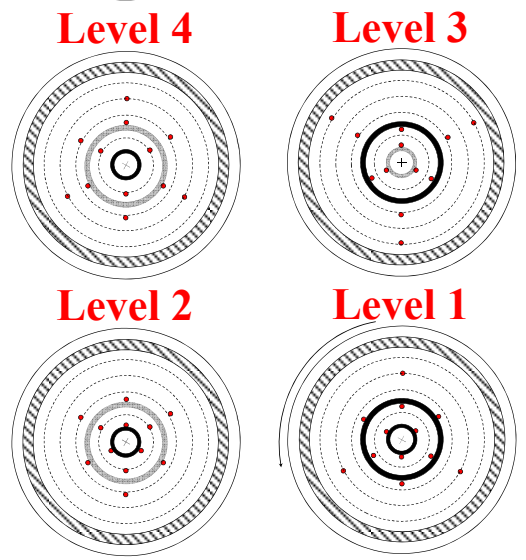

Level 1

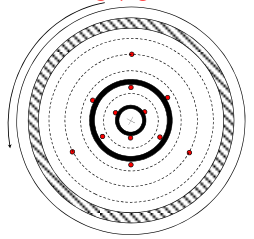

(b)

Figure 3. LIFUS5/Mod3 test section. (a) Schematic drawing of the test section; (b) Layout implementation of the thermocouples.

\subsubsection{Injection Line}

Before each test, water is loaded and brought to the necessary pressure and temperature conditions inside the SBL tank (Figure 1). The water tank is composed of a 11/2" sch.160 vertical pipe, connected at the top to the water charge line and to the argon pressurization cylinder (Figures 4 and 5a), used to maintain the desired water pressure throughout the test. This tank is instrumented with two thermocouples and a DP meter used to monitor the water level during the charging phase and the heating phase.

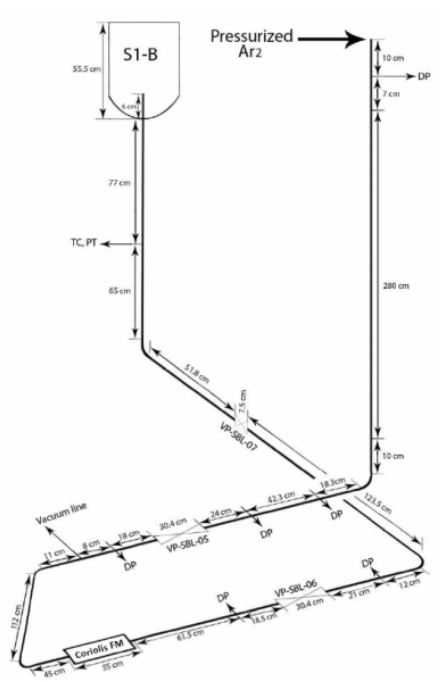

(a)
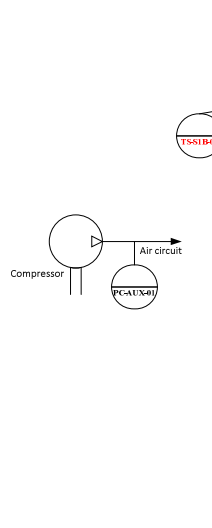

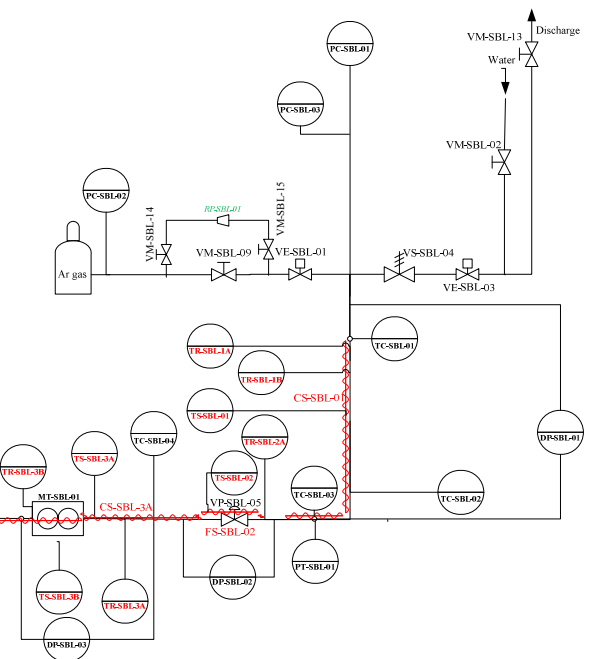

(b)

Figure 4. Schematic drawings of the injection line. (a) Injection line layout and components positioning; (b) injection line P\&ID. 


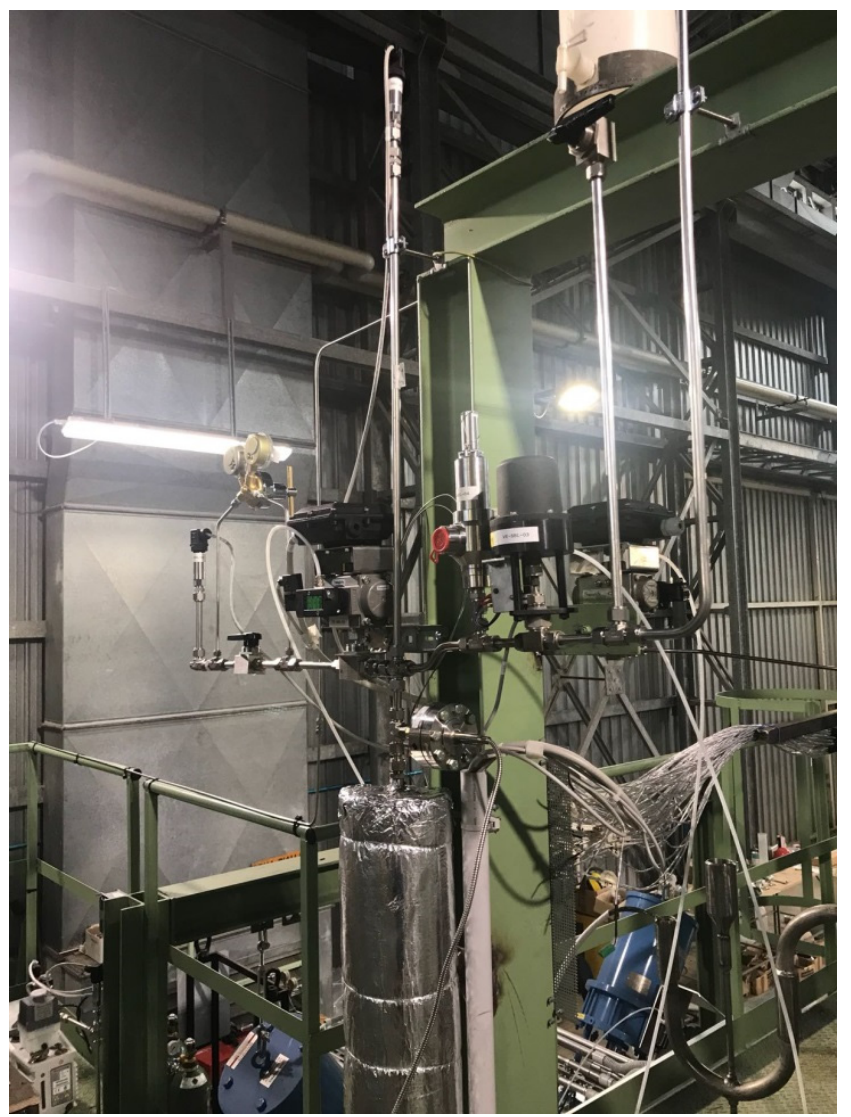

(a)

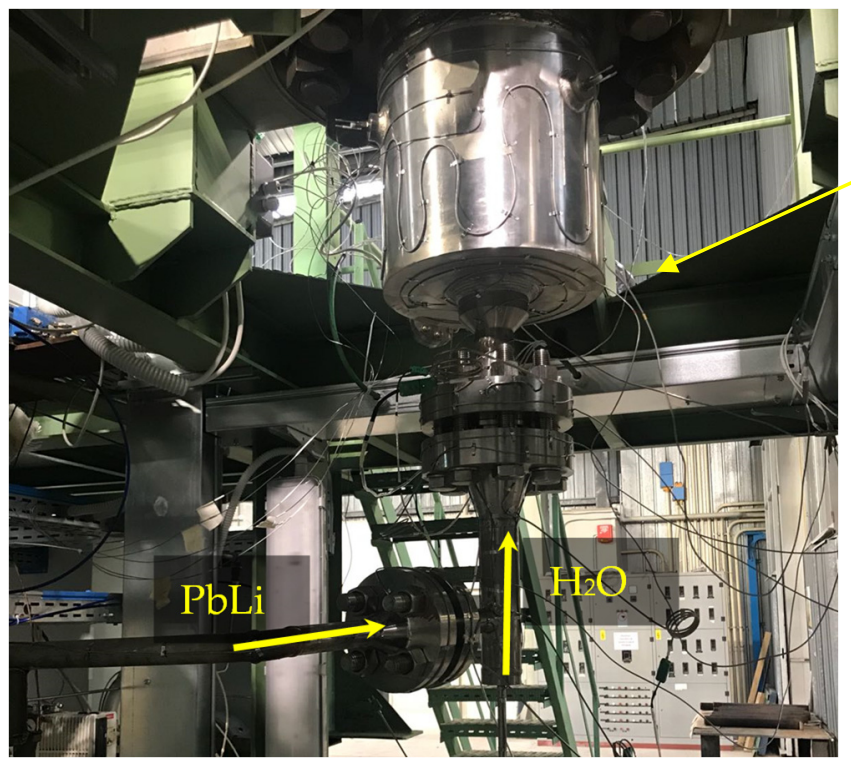

(c)

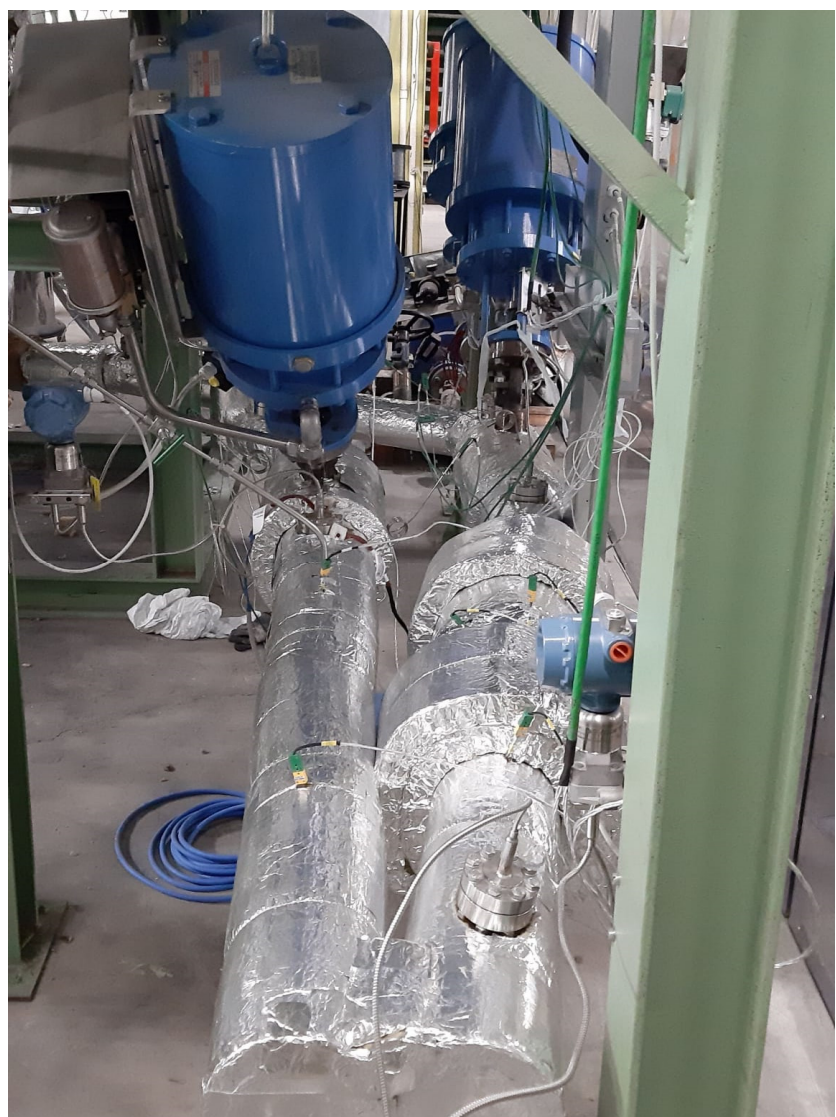

(b)

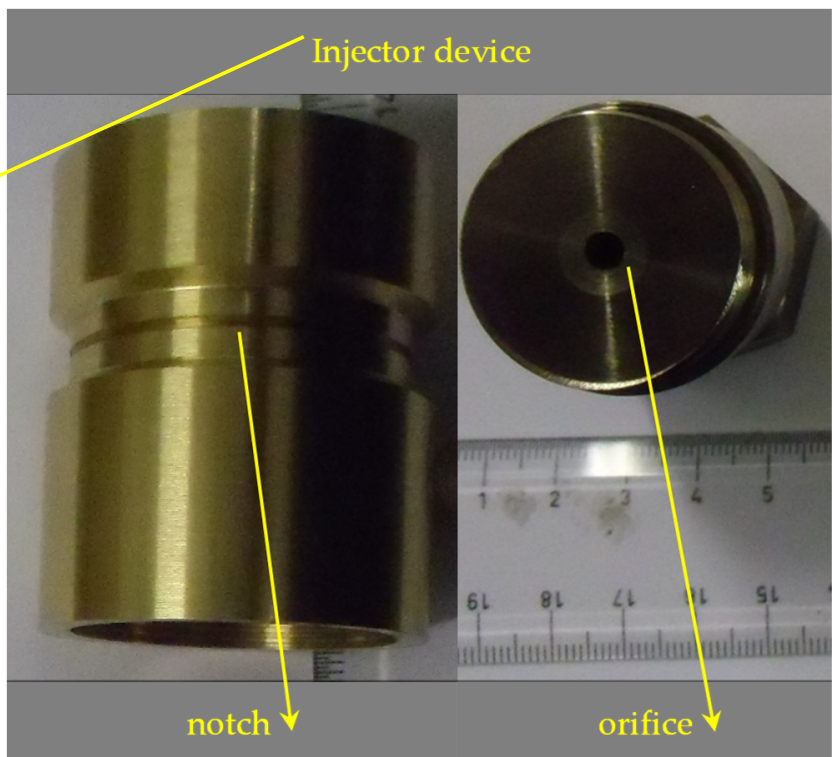

(d)

Figure 5. Detail of the injection line and device. (a) Upper part of the water injection line connected to argon gas cylinder; (b) injection line with valves and Coriolis; (c) injection piping and connection to the S1B vessel; (d) injector cover brass cap with specified notch dimensions.

The water injection line is connected to the bottom of the SBL tank, and it is composed of a $1 / 2$ " Swagelok steel pipe which leads to the S1B vessel, as shown in Figure 5b. This line is instrumented with a series of thermocouples and pressure transducers, and it is heated by means of heating wires surrounded by a thick insulation. Such a configuration 
allows for the maintenance of the water at the right conditions throughout the test and the measurement of its relevant parameters during the injection phase.

The differential pressure meters allow for the measurement of the pressure-drop across the valves. They are mounted in the following positions (Figure $4 b$ ):

- In the SBL vertical section to measure the water level before each test;

- Across valve VP-SBL-05, named: DP-SBL-02;

- Across the Coriolis mass flow meter, named: DP-SBL-03;

- Across valve number VP-SBL-06, named: DP-SBL-03.

The valves VP-SBL-05 and VP-SBL-06 are fast-actuated valves that can reach a fully open position in less than $0.3 \mathrm{~s}$. To achieve this fast actuation time, an independent compressed air line is implemented in the facility to supply the power needed.

Before each test is performed, the whole injection line is evacuated by means of a vacuum pump. This ensures that only water is injected into the reaction vessel, and that no air or argon is present in the system.

The injector device, shown in Figure 5c, is composed of two coaxial pipes, flanged to the bottom of vessel S1B. Water enters the reaction vessel via the innermost line, which is made of $1 / 2$ " Swagelok pipe, and is forced directly inside the interaction zone. A brass plug with a small hole at its center is fixed to the top of this pipe, with the aim of limiting the amount of water injected during each test. The size of the hole performed on the cap can be varied from test to test, to simulate different types of breakage in the real system.

To avoid the premature injection of the water during the initial test phase, a brass cap is placed on top of the plug and soldered to it. This cap, shown in Figure 5d, is built with a notch, which is engineered to break at the desired test pressure. With this system, the experimenters can regulate, with precision, both the mass flow rate of the injected water (by means of the orifice diameter) and the pressure at which the injection occurs, i.e., the pressure at which the cap ruptures (by means of the notch depth).

The two tanks act, respectively, as a storage tank for unused PbLi and as a dump tank for depleted PbLi. Prior to each test, the alloy is loaded into the reaction vessel from tank S4B1, and after each test, the depleted alloy is discharged into tank S4B2 (Figure 6). This procedure ensures the avoidance of the contamination of fresh $\mathrm{PbLi}$ with oxides and other reaction products. The tanks are instrumented to allow for temperature and level control of their content.

\subsubsection{Expansion Line}

The expansion vessel, S3V, acts as a safety volume to collect reaction products such as water vapor, hydrogen, or $\mathrm{PbLi}$ in case of a rupture disk breakage. It has a volume of $2000 \mathrm{~L}$ and a design pressure of $10 \mathrm{bar}$. To protect the facility from overpressure during the tests, the line connecting $\mathrm{S} 1 \mathrm{~B}$ and the relief tank, S3V, is equipped with two rupture disks mounted in series. The first one has a diameter of 2" and is rated for 190 bar at a temperature of $400^{\circ} \mathrm{C}$. The second one has a diameter of $3^{\prime \prime}$ and is rated for 154 bar at $450{ }^{\circ} \mathrm{C}$.

\subsubsection{Hydrogen Extraction Line}

Following each test, the gas composition inside vessel S1B will change from the initially pure argon to a mixture of argon, hydrogen, and unreacted water vapor. This mixture will be extracted from two spillage points and quantitively analyzed by means of a gas analyzer (labelled MS-H2M-01 on the P and ID of Figure 1).

The instrument working principle is based on the measurement of the thermal conductivity variation of the gas mixture. This procedure is carried on at a pressure of $2 \mathrm{bar}$ and at a specific mass flow rate, and these conditions are met by using a pressure reducer and a mass flow meter and controller.

Data from the gas analyzer and from the mass flow meter are acquired using a dedicated system, which is, in turn, connected to the main control system. 


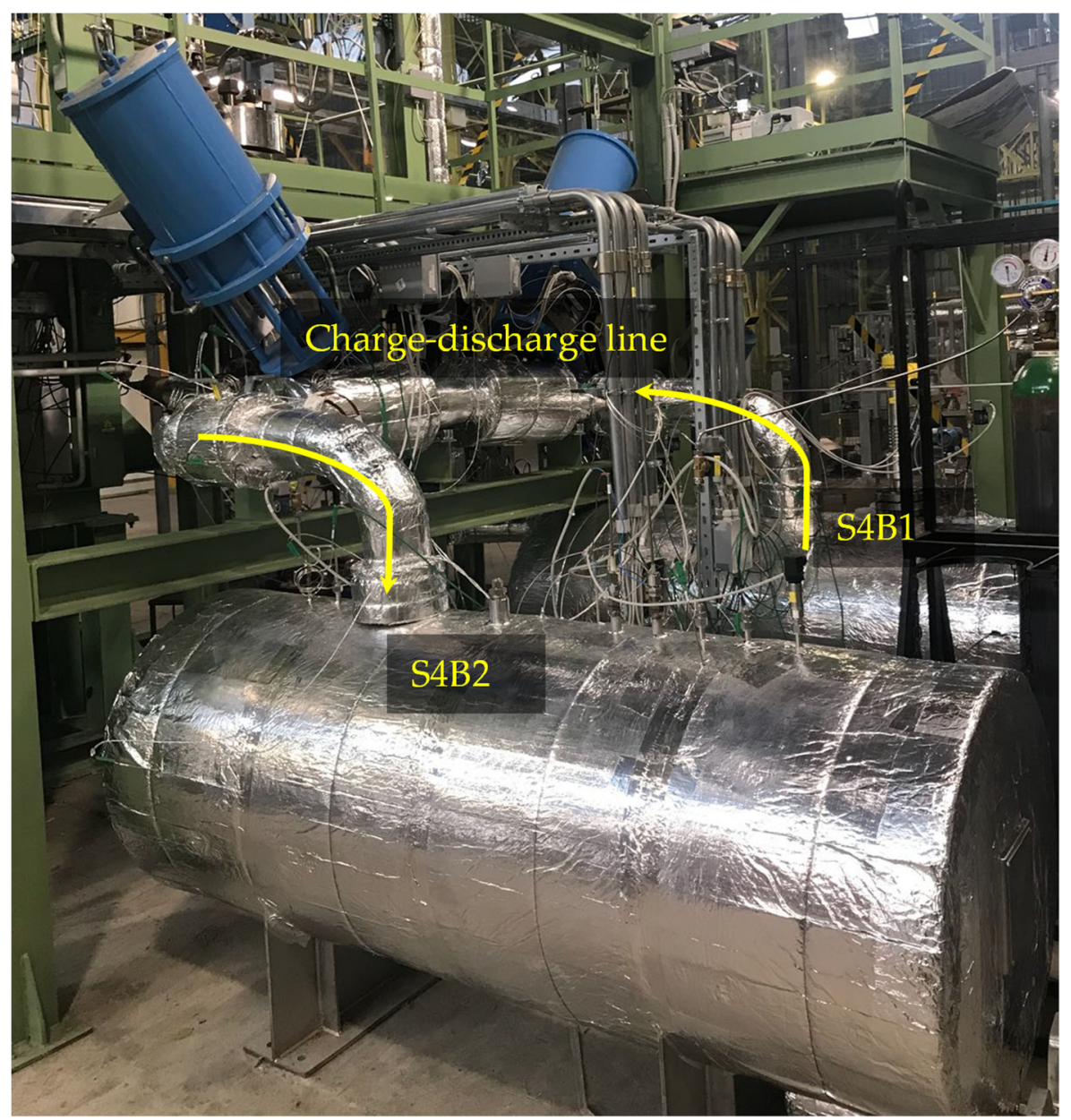

Figure 6. Storage (S4B1) and drain (S4B2) tanks, loading and discharge lines.

\subsubsection{Instrumentation and Control Units}

The Data Acquisition and Control Subsystem (DACS) architecture of this facility is subdivided into two separate sections: the real-time control and data acquisition, and the control, interlock, and safety system. The facility is equipped with a wide variety of sensors to acquire all the relevant thermo-dynamical and mechanical data, such as pressure, temperature, and strain. These sensors are constantly acquired at $1 \mathrm{~Hz}$ during facility operation, while during each test, thermocouples are acquired at $50 \mathrm{~Hz}$ and fast pressure transducers at $10 \mathrm{kHz}$.

To control and operate the facility, a series of pressure reducers and manual, pneumatic, safety, and electro valves are installed in various points. All these components are operated by the experimenter via the control software.

\subsubsection{Test Matrix}

The Series-E test matrix is reported in Table 3. This test matrix was designed with the aim of performing tests at conditions relevant to the WCLL BB design [1-4]. In particular, during a postulated WCLL-BB in-box LOCA, the phenomena and processes occurring in the $\mathrm{PbLi}$ /water interaction are governed, firstly, by thermodynamic parameters, and then by chemical reaction. All phenomena strictly depend on the amount of water injected into the BB box, and are sensitive, besides the design of the water and PbLi loops, to:

- $\quad$ The pressure difference between the water circuit and the PbLi, which is the driving parameter of the transient: once pressures in the two systems come into equilibrium, the injection stops;

- The size of the break; 
- Water flow condition: the instauration of choked flow limits the velocity of water itself, while the void fraction of the jet will affect the actual injected mass.

Table 3. Series-E Test Matrix.

\begin{tabular}{cccccc}
\hline Test Series E & $\begin{array}{c}\text { D Orifice } \\
(\mathbf{m m})\end{array}$ & Water T $\left({ }^{\circ} \mathbf{C}\right)$ & PbLi T $\left({ }^{\circ} \mathbf{C}\right)$ & $\begin{array}{c}\text { Injection } \\
\text { Time (s) }\end{array}$ & $\begin{array}{c}\text { Injection } \\
\text { Pressure (bar) }\end{array}$ \\
\hline$\# 1$ & 4 & 295 & 330 & 1 & 155 \\
$\# 2$ & 4 & 295 & 430 & 1 & 155 \\
$\# 3$ & 1 & 295 & 330 & 0.5 & 155 \\
$\# 4$ & 2 & 295 & 330 & 1 & 155 \\
$\# 5$ & 1 & 295 & 330 & 1.5 & 155 \\
$\# 6$ & 4 & 295 & 380 & 1 & 155 \\
$\# 7$ & 2 & 295 & 380 & 1.3 & 155 \\
$\# 8$ & 1 & 295 & 380 & 2 & 155 \\
\hline
\end{tabular}

In order to investigate these phenomena, the test matrix was based on executed tests with varying diameters of the injection orifice, injection times, and $\mathrm{PbLi}$ temperatures. For all the tests, the injection pressure in the water line was fixed at $155 \mathrm{bar}$, and the temperature set to $295^{\circ} \mathrm{C}$.

\subsection{Code Nodalizations}

The post-test analyses have been performed with the beta version of SIMMER-III, modified for fusion application by the University of Pisa, and identified as "SIMMER-III Ver. 3F Mod. 0.1". This version derives from SIMMER code Ver.3F [25,26], and the main difference is the implementation of the chemical reaction between PbLi and Water [6]. The code SIMMER-III was used both in standalone mode and in a coupled mode with RELAP5/Mod3.3; the coupling technique was created, and is still under development, at the University of Pisa $[17,18]$.

SIMMER-III is a two-dimensional, multi-velocity field, multi-phase, multi-component, Eulerian fluid-dynamics code which can be coupled with a structure model (fuel pin) and a spacetime and energy-dependent neutron kinetics model. The fluid-dynamics portion, which constitutes about two-thirds of the code, is interfaced with the structure model through heat and mass transfer at the structure interfaces, while the neutronics portion can provide nuclear heat sources based on the mass and energy distributions calculated by the other code elements.

The basic geometric structure of SIMMER-III is a two-dimensional cylindrical (R-Z) system. Therefore, all the nodalizations developed through SIMMER-III to model the LIIFUS/Mod3 main components assume an axially symmetric cylindrical geometry. It is important to notice that this means losing information on the evolution on the azimuthal direction.

The facility set-up for the nodalization is shown in Figures 7 and 8. It is constituted by 5 main parts:

- $\quad$ The injection line (blue dashed line in Figures 7 and 8):

- Coupled calculation: fully nodalized with RELAP5;

- Standalone calculation: reduced to a short vertical section below the S1B;

- $\quad$ The reaction vessel S1B (including Test Section);

- The expansion line (including the first rupture disk);

- The hydrogen extraction line (up to the collecting valve);

- The thermocouple supporting passage (gooseneck). 


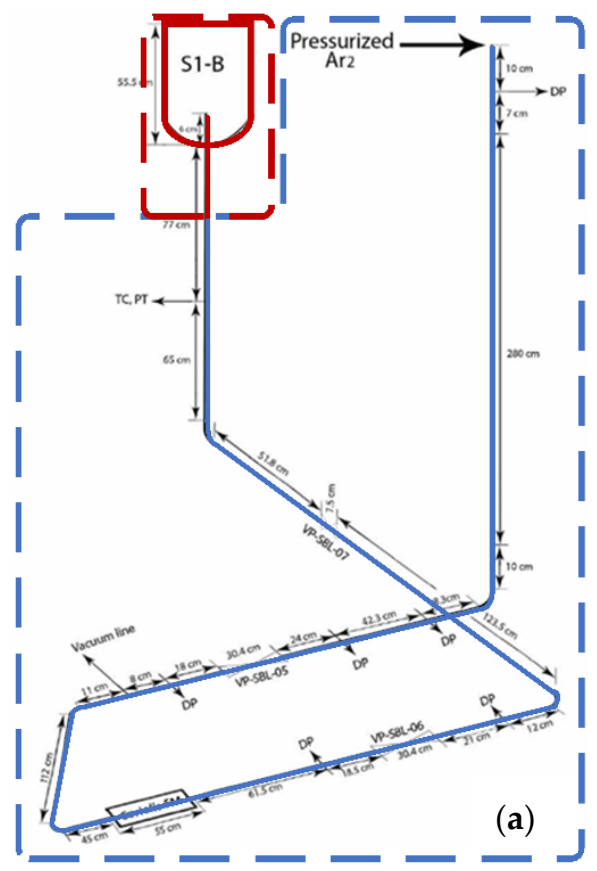

(b)

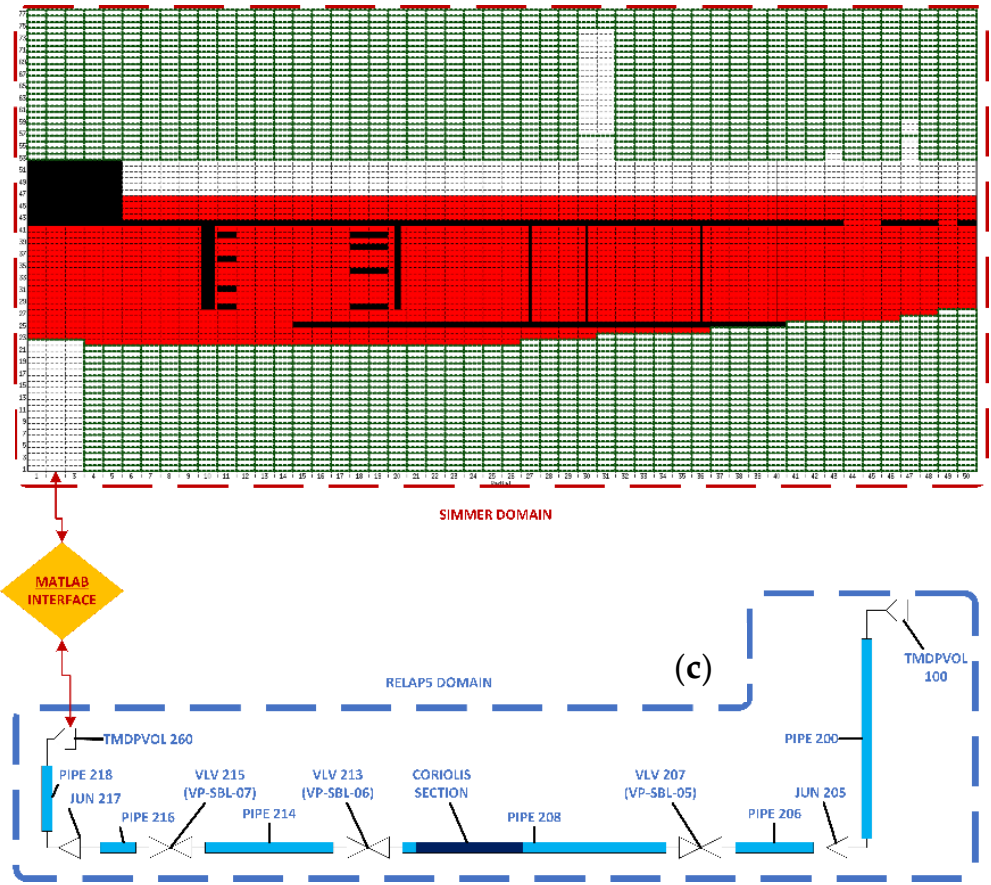

Figure 7. Scheme of coupled codes nodalization. (a) LIFUS5/Mod3 facility and coupling tool interface; (b) S1B modeled by SIMMER III; and (c) injection line modeled by RELAP5/Mod3.3.

The SIMMER-III geometrical domain is obtained by 50 radial and 77 axial mesh cells (Figure 8a). In Figures 7 and 8, the colors distinguish the different fluids and structure materials, as set at the beginning of the transient $(t=0 \mathrm{~s})$. Therefore, the PbLi is represented in red, the water in blue, the argon cover gas (and the hydrogen produced by the reaction) in white, the non-calculation zones are highlighted by a green mesh fence, and SS316 in black as the structural material. The correspondence of the main dimensions of LIFUS5/Mod3 and the SIMMER-III reference model is reported in Table 4.

Table 4. SIMMER-III reference model and LIFUS5/Mod3 facility: main dimensions.

\begin{tabular}{|c|c|c|c|c|}
\hline Region & Dimension & SIII & L5/M3 Facility & SIII Cells \\
\hline \multirow{3}{*}{ S1B } & $\mathrm{H}(\mathrm{m})$ & 0.575 & 0.555 & $22-52$ \\
\hline & $\mathrm{D}(\mathrm{m})$ & 0.2614 & 0.257 & $1-50$ \\
\hline & $\mathrm{V}(\mathrm{L})$ & 26.575 & 26.590 & - \\
\hline \multirow{2}{*}{$\begin{array}{l}\text { Free gas } \\
\text { (in S1B) }\end{array}$} & $\mathrm{H}(\mathrm{m})$ & - & -0.04 & NN-52 \\
\hline & $\mathrm{V}(\mathrm{L})$ & 3.4 & 3.554 & - \\
\hline \multirow{3}{*}{ Inj-device } & $\mathrm{H}(\mathrm{m})$ & 0.02 & 0.02 & 22 \\
\hline & $\mathrm{D}(\mathrm{m})$ & 0.0094 & 0.0094 & $1-3$ \\
\hline & $\mathrm{D}_{\text {orifice }}(\mathrm{m})$ & 0.002 & 0.002 & 1 \\
\hline \multirow{3}{*}{ Inj-line } & $\mathrm{H}(\mathrm{m})$ & (variable) & $\sim 6.8$ & $1-22$ \\
\hline & $\mathrm{D}(\mathrm{m})$ & 0.0094 & 0.0094 & $1-3$ \\
\hline & $\mathrm{D}(\mathrm{m})$ & 0.0094 & & $1-3$ \\
\hline
\end{tabular}

The reference mesh cells for the temperature analysis inside the S1B and for the pressure measuring, representing the position of installed thermocouples and pressure sensors in S1B, are listed in Table 5. 

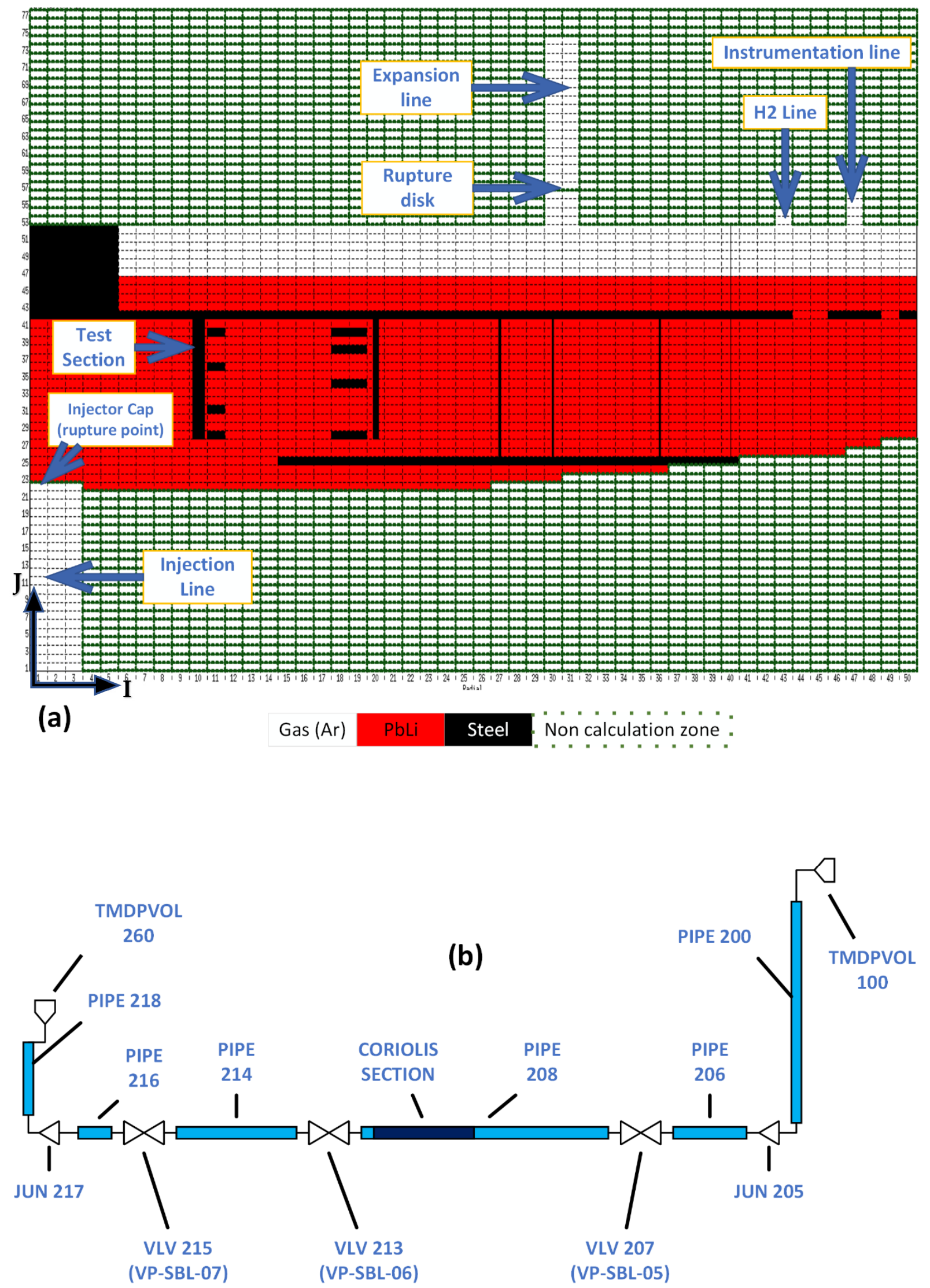

Figure 8. Detailed code nodalization. (a) SIMMER-III nodalization (not on scale) for LIFUS5/Mod3 facility, used in Standalone and coupled analysis; (b) RELAP5/Mod3.3 nodalization of the injection line (only pipe lengths on scale). 
Table 5. Location of the TCs and PTs on the SIMMER-III reference model.

\begin{tabular}{|c|c|c|c|c|c|c|c|}
\hline \multicolumn{8}{|c|}{ Installed (TCs), Inside S1B } \\
\hline & Ring 1 & Ring 2 & & & Ring 4 & Ring 5 & Ring 6 \\
\hline \multirow[b]{2}{*}{ Level 1} & $(12,28)$ & \multirow[b]{2}{*}{-} & $(26,28)$ & $(28,28)$ & \multirow[b]{2}{*}{-} & $(35,28)$ & \multirow[b]{2}{*}{-} \\
\hline & $\begin{array}{l}\text { TC-R11-L1 } \\
\text { TC-R13-L1 }\end{array}$ & & $\begin{array}{l}\text { TC-R31-L1 } \\
\text { TC-R32-L1 } \\
\text { TC-R33-L1 }\end{array}$ & $\begin{array}{l}\text { TC-R34-L1 } \\
\text { TC-R35-L1 } \\
\text { TC-R36-L1 }\end{array}$ & & TC-R53-L1 & \\
\hline \multirow[b]{2}{*}{ Level 2} & $(12,31)$ & $(19,31)$ & \multicolumn{2}{|c|}{$(28,31)$} & $(31,31)$ & \multirow[b]{2}{*}{-} & \multirow[b]{2}{*}{-} \\
\hline & $\begin{array}{l}\text { TC-R11-L2 } \\
\text { TC-R12-L2 } \\
\text { TC-R13-L2 }\end{array}$ & $\begin{array}{l}\text { TC-R21-L2 } \\
\text { TC-R22-L2 }\end{array}$ & \multicolumn{2}{|c|}{$\begin{array}{l}\text { TC-R32-L2 } \\
\text { TC-R33-L2 }\end{array}$} & $\begin{array}{l}\text { TC-R41-L2 } \\
\text { TC-R42-L2 } \\
\text { TC-R43-L2 }\end{array}$ & & \\
\hline & $(12,34)$ & & \multicolumn{2}{|c|}{$(26,34)$} & $(31,34)$ & & $(41,34)$ \\
\hline Level 3 & $\begin{array}{l}\text { TC-R12-L3 } \\
\text { TC-R13-L3 }\end{array}$ & - & \multicolumn{2}{|c|}{$\begin{array}{l}\text { TC-R31-L3 } \\
\text { TC-R33-L3 }\end{array}$} & $\begin{array}{l}\text { TC-R41-L3 } \\
\text { TC-R42-L3 } \\
\text { TC-R43-L3 }\end{array}$ & - & $\begin{array}{l}\text { TC-R61-L3 } \\
\text { TC-R62-L3 } \\
\text { TC-R63-L3 }\end{array}$ \\
\hline & & $(19,36)$ & \multicolumn{2}{|c|}{$(28,36)$} & $(31,36)$ & $(37,36)$ & \multirow[b]{2}{*}{-} \\
\hline Level 4 & - & $\begin{array}{l}\text { TC-R21-L4 } \\
\text { TC-R22-L4 } \\
\text { TC-R23-L4 }\end{array}$ & \multicolumn{2}{|c|}{$\begin{array}{l}\text { TC-R31-L4 } \\
\text { TC-R32-L4 } \\
\text { TC-R33-L4 }\end{array}$} & $\begin{array}{l}\text { TC-R41-L4 } \\
\text { TC-R42-L4 } \\
\text { TC-R43-L4 }\end{array}$ & $\begin{array}{l}\text { TC-R52-L4 } \\
\text { TC-R53-L4 }\end{array}$ & \\
\hline \multirow[b]{2}{*}{ Level 5} & $(12,38)$ & \multirow[b]{2}{*}{-} & \multicolumn{2}{|c|}{$(26,38)$} & $(31,38)$ & & $(41,38)$ \\
\hline & $\begin{array}{l}\text { TC-R11-L5 } \\
\text { TC-R13-L5 }\end{array}$ & & \multicolumn{2}{|c|}{$\begin{array}{l}\text { TC-R31-L5 } \\
\text { TC-R32-L5 } \\
\text { TC-R33-L5 }\end{array}$} & $\begin{array}{l}\text { TC-R41-L5 } \\
\text { TC-R43-L5 }\end{array}$ & - & $\begin{array}{l}\text { TC-R61-L5 } \\
\text { TC-R62-L5 } \\
\text { TC-R63-L5 }\end{array}$ \\
\hline \multirow[b]{2}{*}{ Level 6} & $(12,40)$ & - & $(26,40)$ & $(28,40)$ & - & - & $(41,40)$ \\
\hline & $\begin{array}{l}\text { TC-R11-L6 } \\
\text { TC-R12-L6 }\end{array}$ & & $\begin{array}{l}\text { TC-R31-L6 } \\
\text { TC-R33-L6 }\end{array}$ & $\begin{array}{l}\text { TC-R34-L6 } \\
\text { TC-R35-L6 } \\
\text { TC-R36-L6 }\end{array}$ & & & $\begin{array}{l}\text { TC-R61-L6 } \\
\text { TC-R62-L6 } \\
\text { TC-R63-L6 }\end{array}$ \\
\hline \multicolumn{8}{|c|}{ Installed (TC, PTs) } \\
\hline \multicolumn{7}{|c|}{ Location } & Cell \\
\hline \multicolumn{7}{|c|}{ Injection line-vacuum part, TC-SBL-05 } & $(1-3,17)$ \\
\hline \multicolumn{7}{|c|}{ Injection line-pressurized part, TC-SBL-01, @ temperature BC } & $(1-3,1)$ \\
\hline \multicolumn{7}{|c|}{ Injection line-pressurized part, PC-SBL-01, @ pressure BC } & $(1-3,1)$ \\
\hline \multicolumn{7}{|c|}{ Injection line-vacuum part, PT-SBL-02 } & $(3,17)$ \\
\hline \multicolumn{7}{|c|}{ Expansion line, rupture disk, PT-S1B-04 } & $(30,52)$ \\
\hline \multicolumn{7}{|c|}{ Reaction vessel (S1B), PT-S1B-01/03 } & $(50,33)$ \\
\hline \multicolumn{7}{|c|}{ Reaction vessel (S1B), PC-S1B-01 } & $(47,53)$ \\
\hline
\end{tabular}

The standalone and coupled version of the SIMMER-III nodalization are essentially the same, the only difference being the vertical length of the cells reproducing the injection line; in the coupled version, this region is reduced to only $30 \mathrm{~cm}$ in order to minimize the influence of SIMMER in the simulation of the pressurization, and therefore, fully exploit the capability of RELAP5 in simulating 1-D pipelines.

\subsubsection{Reaction Vessel S1B}

The reaction vessel, S1B, is modeled by two separate regions; at initial conditions, the primary region includes only liquid $\mathrm{PbLi}(\mathrm{I}=1-50, \mathrm{~J}=45-\mathrm{NN})$. The second region is related to argon as the cover gas at the top and dominated by the cells $(I=6-50, \mathrm{~J}=\mathrm{NN})$; see Figure 8a. NN depends upon the initial conditions of PbLi level. The hemispherical part of the vessel is modeled by adding 6 non-calculation regions as well. 


\subsubsection{Test Section}

The test section is installed to support the instrumentation inside the S1B vessel, specifically for the thermocouples. The test section is divided into two different parts, the upper holed disk-shape part, which is considered as 3 different regions with steel as the cladding material at J = 65 (S-III), and the second part, which contains 6 sets of rods with different lengths for each, plus the spacer rings. The whole test section is represented in 6 different levels by 10 vertical rods and 6 horizontal rings. In Figure 8a, the black cells without green fences show the test parts for the SIMMER reference model.

\subsubsection{Injection Line}

The injection line configuration consists of 4 horizontal and 2 vertical parts, and it is too complex to be modeled with a full domain as a SIMMER-III nodalization; therefore, it was decided to cut it and consider it as an integrated vertical pipe which is connected from the top to the reaction vessel and from the bottom to the boundary cell. With this assumption, all of the bends and relevant losses are translated into orifice coefficients and transferred to the new positions in the vertical direction. In the SIMMER-III nodalization, the injection line started from cell $\mathrm{I}=1-3$, radially, and $\mathrm{J}=1-13$, axially. In the standalone version, it contained 3 different regions, starting from valves VP-SBL-06, and including VP-SBL-07 and 2 pipes; see Figure 8a. The upstream part to the water region was cut and excluded from the reference nodalization, and the acquired data from PC-SBL-01 was used as the boundary condition for post-test calculations.

In the RELAP5 nodalization, the injection line is fully nodalized, reproducing all the main features of the line, including the Coriolis section (Figure $8 \mathrm{~b}$ ). The nodalization consists of volume elements, with a specified area and length. The different volume elements and their properties are listed in Table 6 and shown in Figure 8b. The volume elements are connected to each other using junctions, to which a pressure-drop coefficient can be assigned. The junctions are used here to reproduce the change of orientation of the pipes. The properties of these junctions can be found in Table 6 . The injection line starts with SBL, which is modeled as a pipe with 28 volume elements. The water tank is pressurized by a time dependent volume, representing the argon tank. They are connected together by a single junction. The bottom of SBL is connected via a single junction to a smaller pipe containing 10 volume elements. This pipe is connected to a motor valve, representing VP-SBL-05. The valve can be opened or closed, and it is also possible to assign the timing of action. A valve is only a junction, so the volume elements of this valve are incorporated in the next and previous pipes. After other four pipes, two motor valves, representing VP-SBL-06 and VP-SBL-07, and a junction, the line is connected to a trip valve.

\subsubsection{Expansion Line}

The pipe connecting S1B to S3V (expansion tube) is modeled by an annular tube with an equivalent diameter of $0.0428 \mathrm{~m}$, approximately, at a similar distance from the central $\mathrm{Z}$ axis to preserve the flow area. This toroidal tube is located at $\mathrm{I}=30-31, \mathrm{~J}=76-97$. The rupture disk was specified by adding a virtual walls. However, during post-test calculations, the virtual wall remained closed since no signal was recorded in the expansion line during Series D Tests, which means the rupture disk kept closed during the transient. Since the S3V volume does not take an action during the tests, the S3V expansion vessel was not considered in the post-test analysis.

\subsubsection{Hydrogen Extraction Line}

The hydrogen line is supposed to collect the produced $\mathrm{H} 2$ gas from S1B and conduct it through the hydrogen-analyzer system. In the present models, this part is not completely modeled, but its first part, up to the collecting valve, is considered. The cells $(43,76-77)$ represent the volume as an equivalent region for the reference model. 
Table 6. Characteristics of RELAP5/Mod3.3 nodalization.

\begin{tabular}{|c|c|c|c|c|}
\hline $\begin{array}{l}\text { Component } \\
\text { Number }\end{array}$ & $\begin{array}{l}\text { Hydrodynamic } \\
\text { Component }\end{array}$ & Description & $\begin{array}{l}\text { Length } \\
\text { (m) }\end{array}$ & Area $\left(m^{2}\right)$ \\
\hline 100 & Time-dependent volume & Argon tank & $(-)$ & $(-)$ \\
\hline 200 & Pipe & SBL & 2.8 & $9.069 \times 10^{-4}$ \\
\hline 205 & Single junction & & $(-)$ & \\
\hline 206 & Pipe & & 1.096 & $6.936 \times 10^{-5}$ \\
\hline 207 & Motor valve & VP-SBL-05 & $(-)$ & $6.93 \times 10^{-5}$ \\
\hline \multirow{2}{*}{208} & \multirow{2}{*}{ Pipe } & Normal section & 2.094 & $6.936 \times 10^{-5}$ \\
\hline & & Coriolis section & 1.48 & $6.12 \times 10^{-4}$ \\
\hline 213 & Motor valve & VP-SBL-06 & $(-)$ & $6.93 \times 10^{-5}$ \\
\hline 214 & Pipe & & 1.742 & $6.936 \times 10^{-5}$ \\
\hline 215 & Motor valve & VP-SBL-07 & $(-)$ & $6.93 \times 10^{-5}$ \\
\hline 216 & Pipe & & 0.518 & $6.936 \times 10^{-5}$ \\
\hline 217 & Single junction & & $(-)$ & \\
\hline 216 & Pipe & & 1.4 & $6.936 \times 10^{-5}$ \\
\hline 260 & Time-dependent volume & Coupling interface & $(-)$ & $(-)$ \\
\hline
\end{tabular}

\subsubsection{Boundary and Initial Conditions (BIC)}

The reference calculation starts at $t=0 \mathrm{~s}$, which represents the valve VP-SBL-06 opening. The injector cap rupture is simulated by disappearance of the virtual wall at cell $\mathrm{I}=1, \mathrm{~J}=22$, which recreates the $2-\mathrm{mm}$ orifice. The time at which the injector breaks up is obtained from the specific test experimental data. Since the closest PT to the injector cap is PT-SBL-02, the injection pressure trend is assumed to be the pressure recorded by PT-SBL-02, applied in cells (1-3,1); on the other hand, since, in the coupled calculation, the whole line is simulated, the BC set-up pressure and temperature, obtained from PC-SBL-01 and TC-SBL-01, is imposed at TMPVOL 100. Moreover, the boundary condition of the continuous inflow of injected water is applied in the same mesh cells. The initial conditions of pressure, temperature, filling level of lithium-lead in S1B, and the amount of water are set coherently with the experimental data reported in Table 7.

After setting all BICs, the compiled executive file of SIMMER code was used to, firstly, run the reference model, and later, the other cases, for sensitivity analysis. The calculations lasted for $3 \mathrm{~s}$.

\section{Results}

In the following, the experimental data of Test E4.1 are reported, together with a critical analysis of the results, as well as the numerical post-test simulations obtained in SIMMER-III standalone and RELAP5/SIMMER-III coupled configurations.

\subsection{Test E4.1 Experimental Results}

The test E4.1 was executed on 4 November 2020 at 11:23:42. It corresponded to Test \#4 of the test matrix proposed in the framework of EUROfusion project (Table 3). The injection procedure (see P\&ID in Figure 1) is foreseen to open the valves connecting the argon cylinder to the SBL water line (VM-SBL-09 and VE-SBL-01); thus, the system is pressurized and maintained in this condition to reach the thermal equilibrium. Then, valve VP-SBL05 is opened to permit the filling of the line up to the injection valve VP-SBL-06. The acquisition system is in stand-by, waiting for the injection signal. This signal is activated by the operator when all parameters are correctly checked. Then, the fast acquisition system starts to record the data, and the valve VP-SBL-06 is opened up to the closing signal. The closure of valve VP-SBL-06 is automatically activated after $1 \mathrm{~s}$. The water injection in S1B lasts for $0.93 \mathrm{~s}$ (from cap rupture to VP-SBL-06 fully closed). Once the pressure inside injector reaches rupture limit, the injector breaks and the water starts to flow into reaction vessel S1B and the transient starts. The pressure from the argon cylinder is kept for the whole transient. A valve called VP-SBL-07 is installed to protect VP-SBL-06 from the PbLi drop. The acquisition system continues to record data (pressures, temperatures, levels, and 
so on) up to the end of the test. The acquisition system worked properly. The strain gages and pressure transducers signals were acquired at $10 \mathrm{kHz}$, and the thermocouple signals at $50 \mathrm{~Hz}$.

From the phenomenological point of view, the test can be divided into four different phases:

1. Pressurization of water injection line $(0 \mathrm{~ms}$ to $229.4 \mathrm{~ms})$, from the pressure rise in the injection line (valve VP-SBL-06 starts to open, start of test) to the rupture cap occurrence (start of injection).

2. Water-PbLi interaction (229.4 $\mathrm{ms}$ to $1156.8 \mathrm{~ms}$ ), from the cap rupture occurrence to the full closure of valve VP-SBL-06 (end of injection). This phase can be divided into three different sub-phases:

a. Flashing of injected water (229.4 ms to $245 \mathrm{~ms}$ ), from cap rupture occurrence to the ending of the first pressure peaks.

b. Pressurization dominated by the two-phase thermodynamic interaction $(245 \mathrm{~ms}$ to $420 \mathrm{~ms}$ ), from the ending of the first pressure peaks to the pressure slope change.

c. Pressurization dominated by the single-phase thermodynamic interaction $(420 \mathrm{~ms}$ to $1156.8 \mathrm{~ms}$ ), from the pressure slope change to valve VP-SBL-06 fully closed.

3. Pressurization dominated by the chemical reaction ( $1156.8 \mathrm{~ms}$ to $\sim 20,000 \mathrm{~ms})$, from the full closure of valve VP-SBL-06 to the S1B pressure stabilization.

4. Ending phase ( 20,000 $\mathrm{ms}$ to the End of Test), from the S1B pressure stabilization to the End of Test.

In each of these phenomenological phases, the main parameter trends, such as the pressure in the water line (Figure 9), the pressure (Figure 10) and the strain in the reaction vessel (Figure 11), and the temperatures in the test section (Figure 12), showed different behaviors.

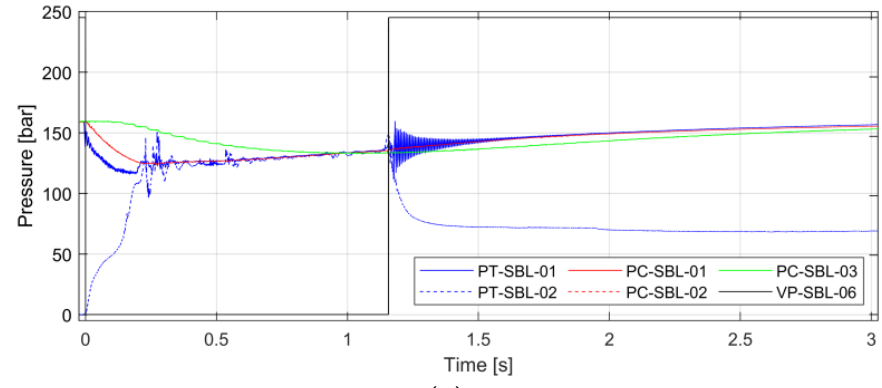

(a)

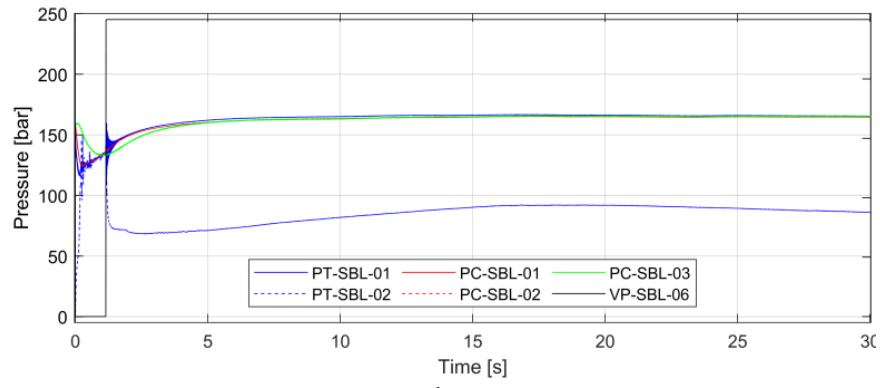

(b)

Figure 9. Pressure time trends in SBL injection line and valve position. (a) zoom on [0-3] s, (b) zoom on [0-30] s.

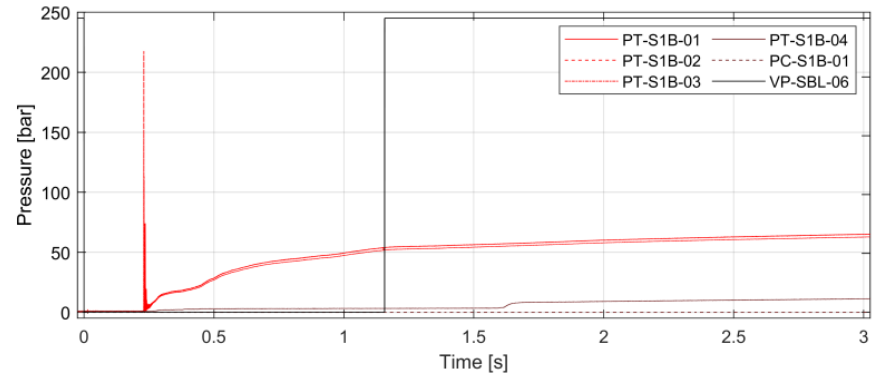

(a)

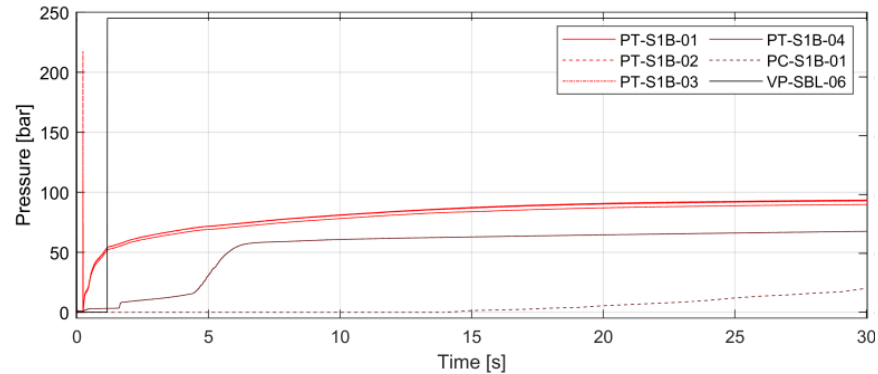

(b)

Figure 10. Pressure time trends in S1B reaction vessel and valve position. (a) zoom on [0-3] s, (b) zoom on [0-30] s. 


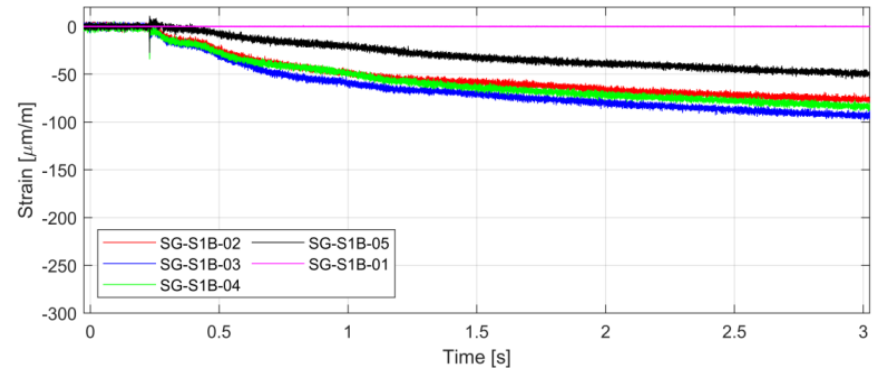

(a)

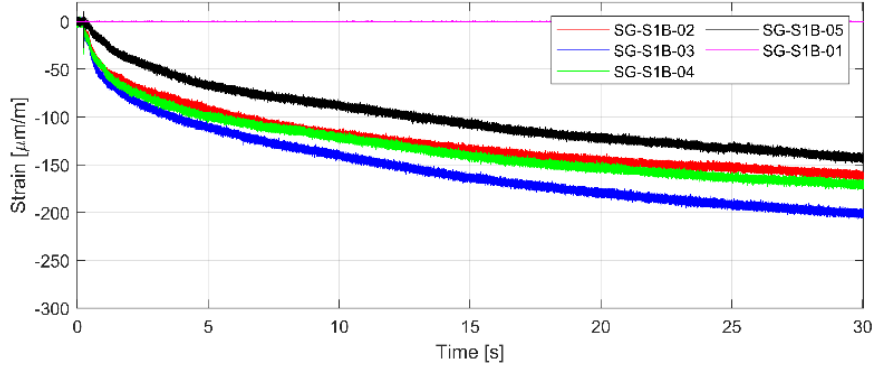

(b)

Figure 11. Strain time trends on external surface of S1B reaction vessel. (a) zoom on [0-3] s, (b) zoom on [0-30] s.
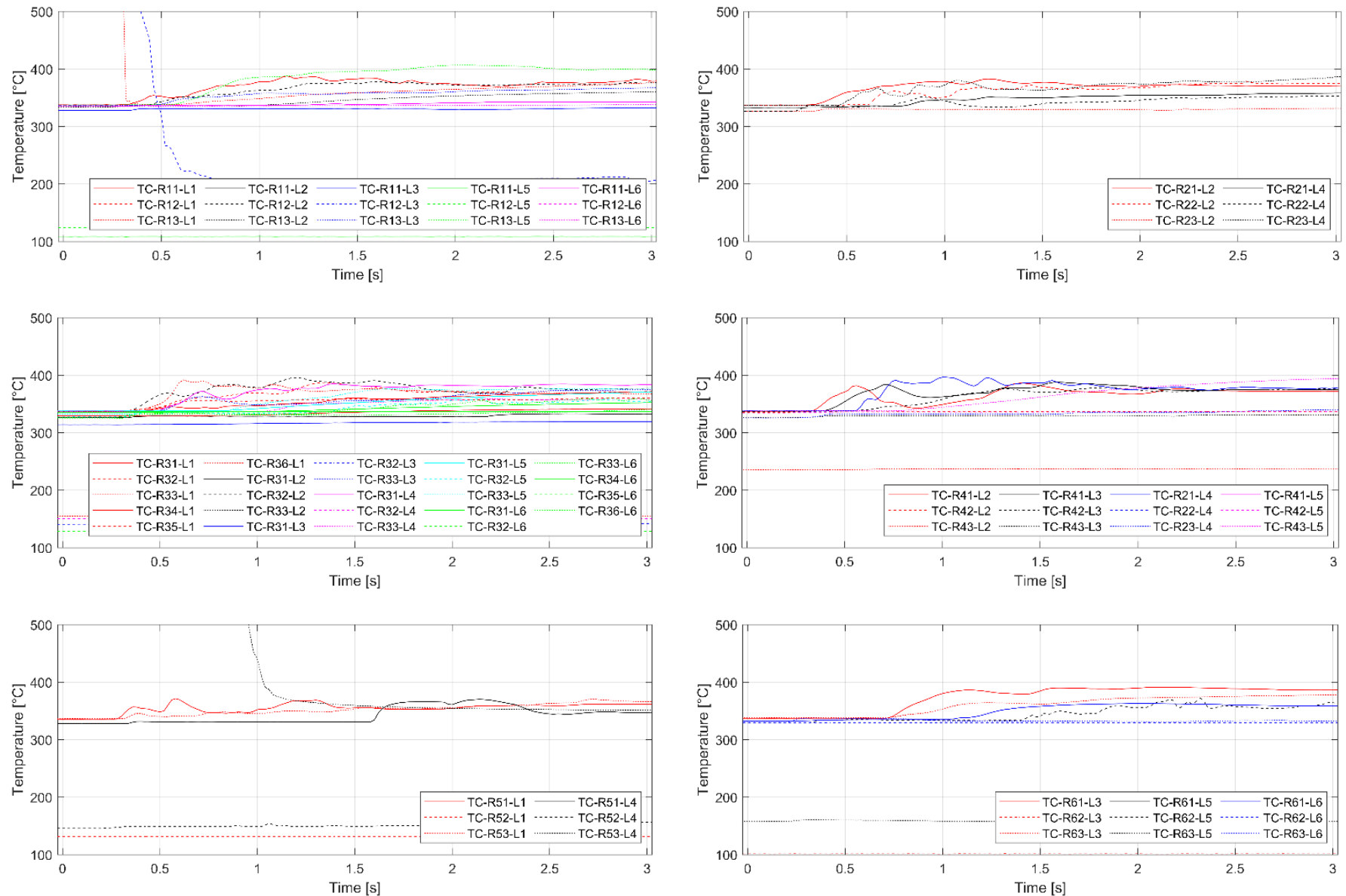

Figure 12. Temperature time trends in S1B at different rings (from Ring 1 to Ring 6, see Figure 3b).

\subsubsection{Pressure Time Trends}

Two fast pressure transducers acquired the pressure trend in the injection line PTSBL-01, positioned in the water tank, and PT-SBL-02, positioned just below the injector. Moreover, two different absolute-pressure transducers, PC-SBL-01 and PC-SBL-03, are installed (Figure 9). The former is able to follow the fast pressure change during the first phase of the test; meanwhile, the latter is not, even if it can be installed at a high temperature. The sensor PC-SBL-02 recorded the pressure in the argon cylinder. In the first phase of the transient, the PT-SBL-02 sensor recorded a pressurization rate of $633.3 \mathrm{bar} / \mathrm{s}$. Once valve VP-SBL-06 was fully opened, the water filled the injection line between valve VP-SBL-06 and the injector cap inside S1Buntil cap rupture, which occurred at a pressure of 146.3 bar. As soon as the cap broke, the second phase started, and water was injected in the reaction vessel and the pressure in the injection line decreased rapidly. PT-SBL-02 recorded 
a decrease from 146.3 bar to about 100 bar, due to the instantaneous increase of volume; then, its decrease was stopped, remaining constant for few tenths of a millisecond, probably due to the two-phase water injection. The pressure in the injection line rose again, up to the constant value of about 125 bar, equal to the pressure recorded by PT-SBL-01 in the SBL tank, until the valve closure instant. After that, the third phase started. The water tank, SBL, and the reaction vessel, S1B, were isolated; therefore. The pressure in SBL increased due to the connection with the upstream argon cylinder, and PT-SBL-02 measured a sudden pressure decrease as a consequence of a disconnected pressurization system. The pressure equalization between S1B and the injection line downstream VP-SBL-06 occurred after the valve closure at about $t=3 \mathrm{~s}$.

Concerning the pressure inside S1B reaction vessel (Figure 10), during the first phase, the initial relative pressure after $\mathrm{PbLi}$ filling was about 0.7 bar. Once the injector cap broke (the second phenomenological phase), the pressurization of S1B was characterized by several peaks, lasting for about $15 \mathrm{~ms}$, due to the water-flashing inside the tank, followed by steam and gas expansion through the perforated top plate of the test section and towards the gas plenum (decrease of pressure), and a new water-flashing. For each peak, different signals were recorded by the fast pressure transducers, reflecting the pressurewave propagation inside the reaction vessel. The PT set in S1B cover gas (PT-S1B-04) showed a delayed pressure increase, due to the gas expansion towards the upper part of the $\mathrm{S} 1 \mathrm{~B}$ reaction vessel. Additionally, the sensor was partially plugged by PbLi splashes; indeed, a difference of about 20 bar was recorded in respect of the other PTs. Up to about $420 \mathrm{~ms}$, the pressure recorded a monotonous increase to almost 20 bar, dominated by the two-phase water interaction, the water evaporation, and partially by the hydrogen generation. Then, the pressure started to increase, again, up to 53 bar at the closure of valve VP-SBL-06. This phase was dominated by the pressurization due to single-phase water interaction, and by hydrogen production and temperature increases due to the exothermic chemical reaction between PbLi and water. Then, during phase 3, the S1B reaction vessel and the injector were in connection, the pressure in the system continued to increase due to the chemical reaction between $\mathrm{PbLi}$ and the injected water, and the hydrogen generation increased, from 53 bar to almost 90 bar.

\subsubsection{Strain Time Trends}

The strain time trends, measured on the outer surface of S1B, are depicted in Figure 11. It is possible to highlight several peaks due to pressure waves propagated in the liquid alloy as a result of cap-breaking and water-flashing. SG-S1B-01, positioned in radial direction on the bottom part of the reaction tank, was defective. On the contrary, the other strain gages positioned on the cylindrical shell of S1B recorded different peaks. The higher values of the first peaks was recorded by SG, positioned in circumferential direction, whilst the axially positioned SG-S1B-05 measured lower values. The SGs showed deformation trends that perfectly overlapped with the pressure trends behavior recorded by PT. At valve closure, the SGs measured values in the range of -26.8 to $-68.1 \mu \mathrm{m} / \mathrm{m}$. Then, during phase 4, the SG recorded a monotonous increase of the deformation rate, until the strains reached an almost-stationary condition. The sensors showed a residual strain at the End of Test (EOT) that could be ascribed to the different working temperature, in respect to the initial one, and to the pressurization of S1B. The SGs set on a circumferential position measured their maximum strain value (respectively, $-173.1,-217.6$, and $-191.4 \mu \mathrm{m} / \mathrm{m}$ for SG-S1B-02/03/04). The strain gage positioned in an axial position on the cylindrical shell of the vessel measured a lower strain of about $-160.2 \mu \mathrm{m} / \mathrm{m}$.

\subsubsection{Temperature Time Trends}

The initial temperature of the $\mathrm{PbLi}$ in $\mathrm{S} 1 \mathrm{~B}$ was about $333.9^{\circ} \mathrm{C}$. During the experimental campaigns, an unexpected phenomenon was observed. Indeed, after each test, a variable number of thermocouples modified their readout behavior, providing unreliable data. It is noted that the involved thermocouples tended to give readouts of temperatures that 
were lower than the expected and differed substantially from the average readout of the thermocouple bundle mounted in the test section. This readout degradation follows a unique behavior, and considering the harsh environment in which these sensors must operate, its cause has been hypothesized to lie in a phenomenon commonly known as "green rot" [27], the common name for referring to the oxidation of the chromium in K-type thermocouples, which typically occurs in high-temperature and reducing environments. K-type thermocouples are partially made of a Ni-Cr alloy, which is normally protected from oxidation by a thin layer of oxide that forms over its surface. However, the presence of a reducing agent (such as hydrogen, generated by the $\mathrm{PbLi}$-water interaction) and the high temperature environment can substantially accelerate the corrosion of the sensing tip.

Due to these considerations, during the tests performed on the LIFUS5/Mod3 facility, an extensive phenomenon of green rot occurred on the thermocouples of the test section, which were exposed to a high-temperature and hydrogen-rich environment. Moreover, the small size of the thermocouples themselves $(0.5 \mathrm{~mm}$ in diameter $)$, and the mechanical stress due to the pressure waves generated by the tests, might have accelerated the degradation. Nevertheless, in the subsequent data analysis, anomalous thermocouples have been individuated, and their data discarded, to avoid the degradation of the results. The classification of anomalous thermocouples was performed by carefully analyzing the signal provided during the PbLi charging phase, when the test section was in thermal equilibrium with the PbLi. In this condition, in fact, the high thermal conductivity of the alloy caused all of the thermocouples at the same depth to read the same temperature values and allowed for the individuation of the broken ones.

The temperature time trends measured by all the TCs set on the levels and rings of the test section are shown in Figure 12. The nomenclature TC-RXX-LY defined the position of the thermocouples in the ring and in the level, i.e., the code TC-R31-L2 specifies the first TC (starting from the established position shown in Figure 2b, in counterclockwise direction) positioned in Ring 3 and Level 2. Each figure reports the temperature time trends of TCs installed in the same ring. Ring 1 and Level 1 are the closest to the injector, Ring 6 and Level 6 are the farthest from it. In test E4.1, the effect of the thermodynamic interaction between $\mathrm{PbLi}$ and water, characterized by the cooling of the melt due to the water jet expansion, did not appear, which is clear evidence that the jet was almost spread in S1B. On the contrary, at the interface between two fluids, the chemical reaction occurs, generating hydrogen and heat. Indeed, the temperatures increased, as recorded by all the TCs installed in the test section. The temperature trends showed that the chemical reaction prevailed in the middle levels (Level 3, Level 4, and Level 5) and was almost spread in a radial direction; indeed, not-significant peaks are recorded (the highest value of $439.67{ }^{\circ} \mathrm{C}$ was reached by TC-R61-L3 at $16.54 \mathrm{~s}$ ), but the heat generated by the chemical reaction led to a general increase of temperature in the whole system with an average difference of about $20^{\circ} \mathrm{C}$ (up to valve closure). Additionally, after the valve closure, the temperatures in the reaction zone increased again as a result of the continuous chemical reaction between the water already injected and the PbLi.

\subsubsection{Hydrogen Production}

Finally, concerning the measurement of the hydrogen produced by the reaction, it was necessary to obtain the amount of injected water during the test in order to verify the reliability of the hydrogen gas analyzer. This amount is evaluated a posteriori, considering the integration of the mass flow rate evaluated by the Coriolis mass flow meter (Figure 13a). The mass flow meter recorded a delayed measure, which was not fully able to follow the fast dynamic of the injection. Indeed, the instrument continued to measure once the injecting valve was already closed. However, the amount of injecting water was evaluated considering the following rationale:

- At SoT, the facility condition was: valve VP-SBL-05 opened, and valve VP-SBL-06 closed; DP-SBL-01 (Figure 13b) measured 90.8 mbar, which corresponded to an amount of water in the SBL line equal to $944 \mathrm{~g}$; 
- During the injection, DP-SBL-01 measured 0.0 bar; therefore, all the water was injected through the line;

- At the end of the test, a part of the water that remained trapped in all the injection lines was collected and weighted, with a result of $750 \mathrm{~g}$;

- This result, considering the differential pressure sensor measurement, permitted the obtaining of the injected water, with a result of $944-750 \mathrm{~g}=194 \mathrm{~g}$;

- The Coriolis mass flow meter measured an integral value of $395 \mathrm{~g}$;

- Some of the water remained trapped between valve VP-SBL-06 and valve VP-SBL-07. The volume of this section of the line is equal to $0.14 \mathrm{~L}$, which corresponds to a mass of $111 \mathrm{~g}$ (at $250^{\circ} \mathrm{C}$, temperature effectively recorded);

- The amount of injected water, considering the Coriolis mass flow meter measure, permitted the obtaining of the injected water, with a result of $395-111=284 \mathrm{~g}$;

- Considering the double-check of the injected water, the estimation gave a range between 194 and $284 \mathrm{~g}$.

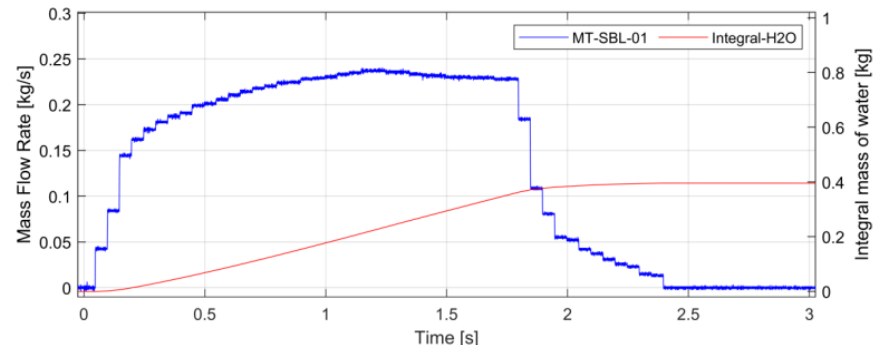

(a)

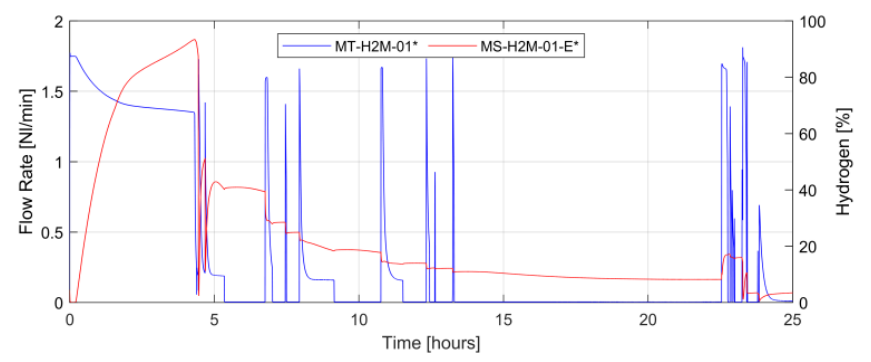

(c)

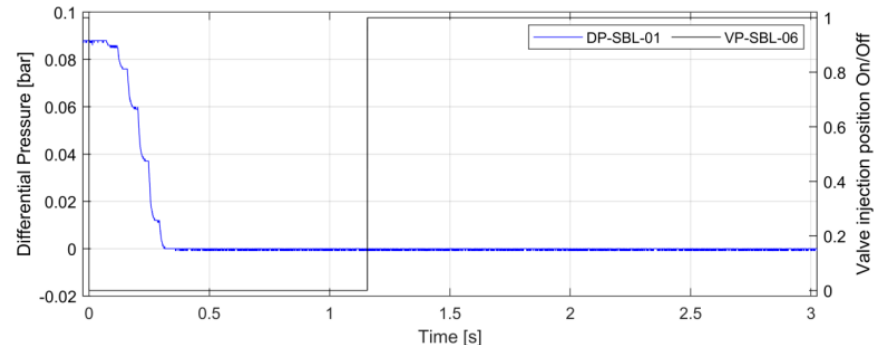

(b)

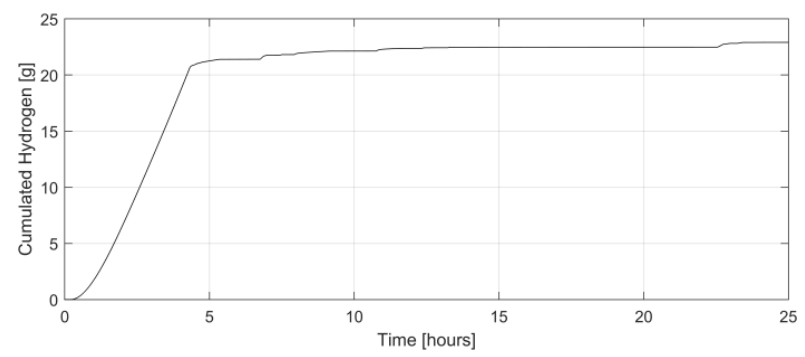

(d)

Figure 13. (a) Injected water mass flow rate and integral value; (b) differential pressure measured in the SBL tank; (c) gas mass flow rate (MT-H2M-01) and hydrogen concentration percentage (MS-H2M-01) time trends; (d) cumulated hydrogen time trend.

Since, in test E4.1, the rupture disk did not fail, the hydrogen measurement proceeded from the extraction line, opening the valve VE-S1B-01, and then moved towards the hydrogen-measurement system by opening VP-S1B-02 and VP-S1B-07 (see P and ID in Figure 1). The analysis of the gas proceeded for $24 \mathrm{~h}$, injecting argon gas in reaction vessel S1B once the pressure decreased, to try of remove all the hydrogen produced by the chemical reaction. Since the gas-flow controller was calibrated to a gas mixture of $50 \%$ Ar and $50 \% \mathrm{H}_{2}$, the mass flow rate recorded by MT-H2M- 01 was corrected a posteriori by a conversion factor based on FLUIDAT ${ }^{\circledR}$ Bronkhorst database, and on the basis of the amount of volume concentration calculated by the analyzer (the symbol * in Figure 13c highlights the correction). The maximum value of recorded concentration was $93.4 \%$, and the maximum mass flow rate was $1.8 \mathrm{nl} / \mathrm{min}$. Considering that, a total of $510.6 \mathrm{nl}$ of gas passed through the flow meter, containing $22.9 \mathrm{~g}$ of hydrogen (Figure 13d). This result is in the foreseen range and was calculated by the stoichiometry. Indeed, for a range of 194-284 $\mathrm{g}$ of injected water, the hydrogen produced by the reaction shall be in the range between 10.8 and $31.6 \mathrm{~g}$, according to the predominant reaction between PbLi and water. 


\subsection{Numerical Results in Standalone and Coupled Configurations}

This section summarizes and discusses the major results obtained with the numerical simulations of test E4.1, comparing the results of the two configurations of the codes (standalone and coupled) with the experimental data and trends. Table 7 provides an overview of the main conditions of the experiment and simulations.

Figures 14-18 show the evolution of the pressures and temperatures in the injection line and in the S1B vessel, as predicted by the codes in the standalone and coupled configurations (SIMMER-III and SIMMER-III/RELAP5, respectively). The simulated time spans from the starting of the transient (time 0, opening of valve VP-SBL-06) to $3 \mathrm{~s}$. It is important to notice that the whole experiment lasts much longer $(60 \mathrm{~s})$. However, this part of the numerical work was focused on the simulation of the injection transient; therefore, a time duration up to $3 \mathrm{~s}$ was considered sufficient for the evaluation of the performances of the codes.

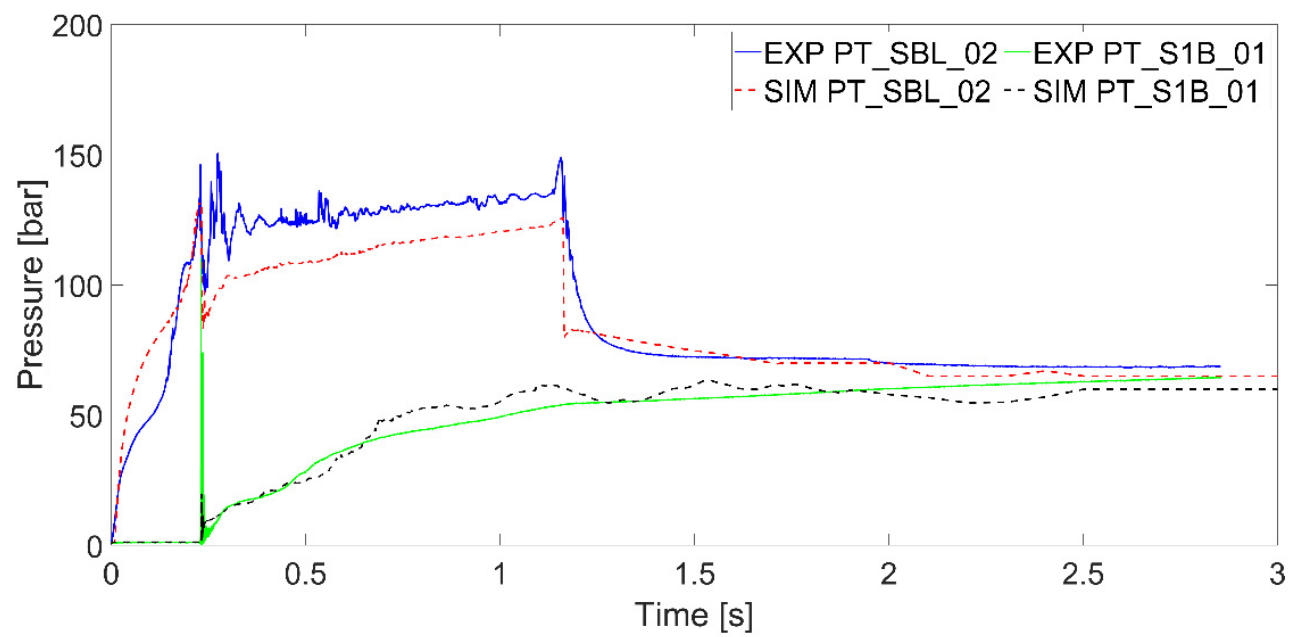

Figure 14. Standalone simulation-pressure evolution in the injection line and in S1B, compared with experimental data $(\mathrm{PT})$.

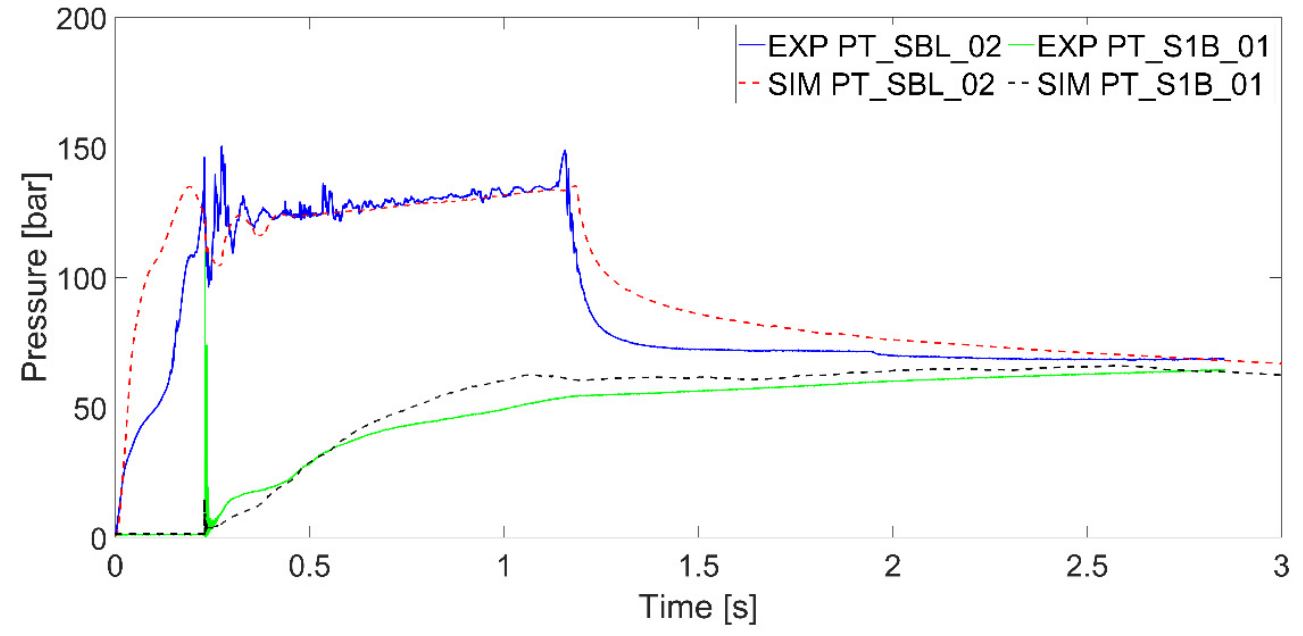

Figure 15. Coupled simulation-pressure evolution in the injection line and in S1B, compared with experimental data (PT). 


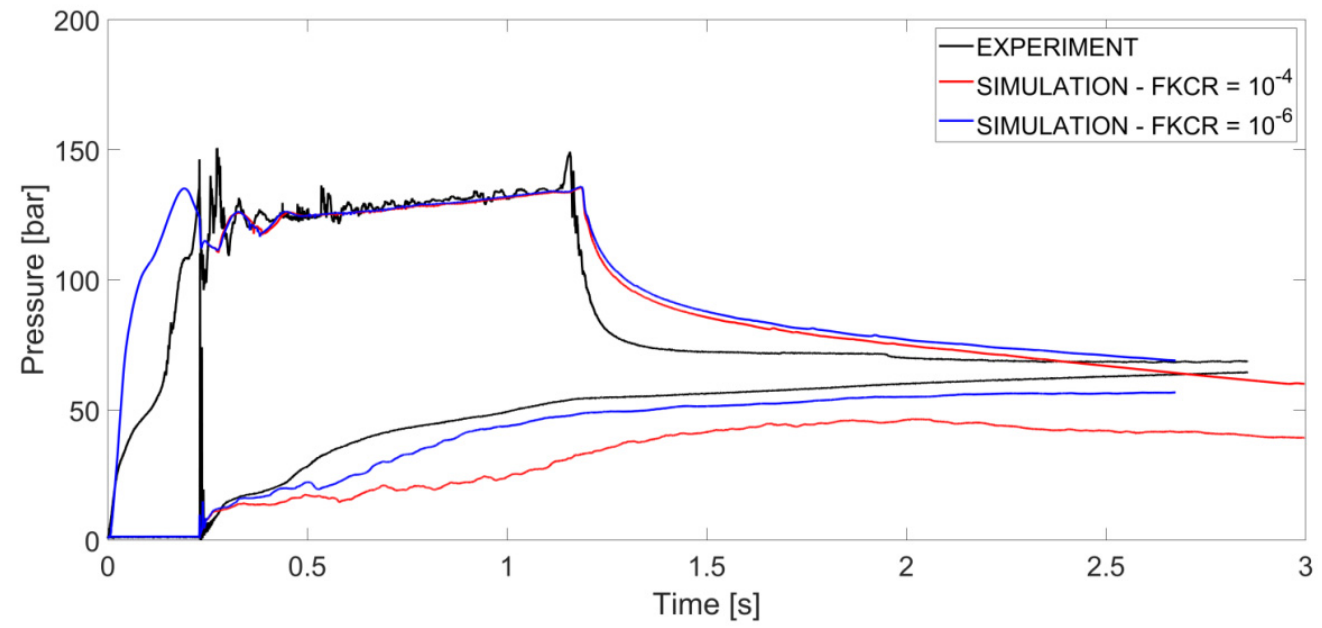

Figure 16. Coupled simulation-pressure evolution in the injection line and in S1B, compared with experimental data at different reaction rates.
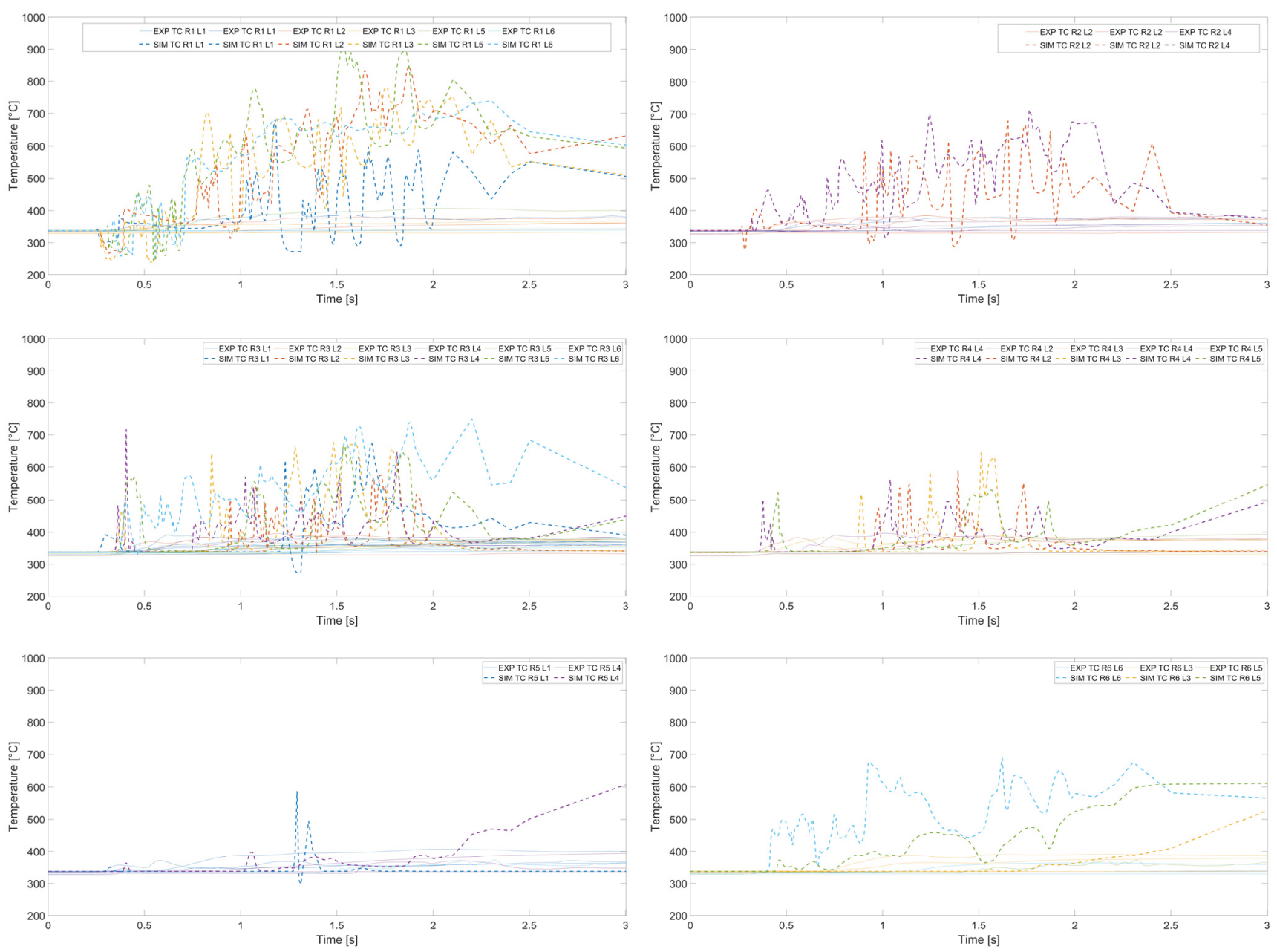

Figure 17. Temperature evolution in S1B for standalone simulations at different radial and axial positions (refer to Table 5). 

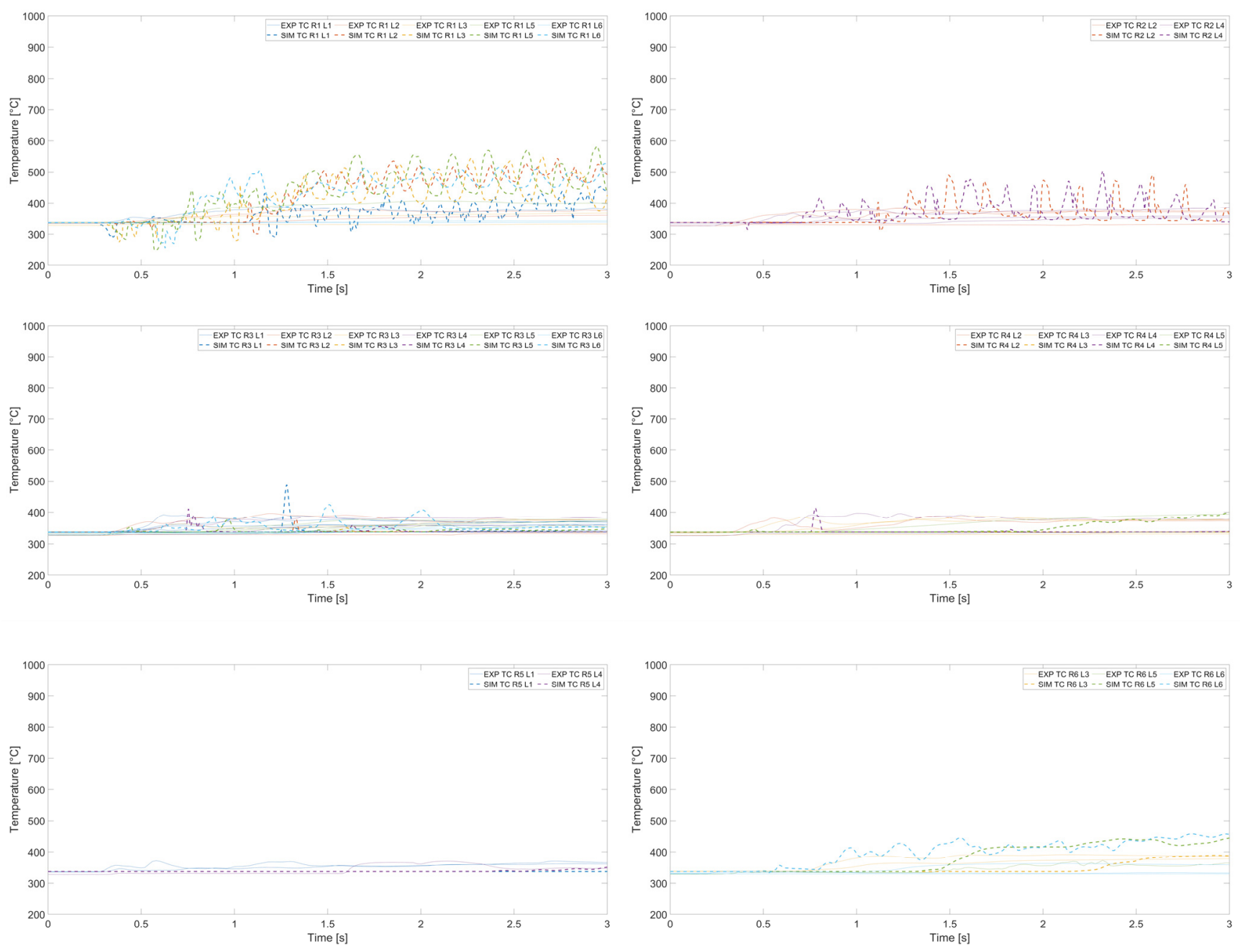

Figure 18. Temperature evolution in S1B for coupled simulations at different radial and axial positions (refer to Table 5).

\subsubsection{Pressure Evolution}

The evolution of the pressure is presented in Figures 14 and 15, compared with experimental data. Regarding the first transient period (i.e., the pressurization of the line, from 0 to $0.2 \mathrm{~s}$ ), the pressure increase rate was well-captured only for the very first moments; afterwards, for up to $0.2 \mathrm{~s}$, both the configurations show a significant overprediction of the pressure inside the line.

For the standalone configuration, the possibility of analysis remains very limited, with the only "tunable" parameter being the so-called orifice coefficients, which affect the pressure-drops through the numerical cells; furthermore, the significant discrepancies between the standalone nodalization and the real geometry of the line make it quite difficult to understand the causes of this overprediction. For instance, since SIMMER standalone simulates the whole injection line as a vertical pipe, it is difficult to perform analyses on the effect of water position and the water quality in the line. However, the critical point identified is the absence of any kind of delay regulation of the opening time of the injection valve in SIMMER: the valve VP-SBL-06 is only represented by a virtual wall, which instantaneously disappears at the valve-rupture time, without simulating opening-time intervals; this might lead to a not-sufficiently precise simulation of the pressurization.

On the other hand, in the coupled configuration, exploiting RELAP5 features, several attempts were carried out to improve the quality of the pressurization, through sensitivity analyses (not shown here) of the pressure-drop coefficients of the junctions and valves, the position and quality of the water inside the line, and the opening rate of the VP-SBL-06 
valve. However, it was not possible to correct the overprediction of the pressure increase rate and, as a conclusion of the sensitivity analysis, it is presumed that the most probable cause is the opening law of the valve, which is modeled linearly by default in RELAP5. Actually, it is possible to impose a customized opening law on RELAP5, but this study of the real opening law was deemed beyond the scope of this work for the time being. It will certainly be considered for further investigation.

For all these reasons, it was chosen to simulate the rupture of the cap at the time in which the pressure in the SIMMER injection line reached a value close to both the experimental rupture pressure and time.

At a time around $0.2 \mathrm{~s}$, the virtual wall (SIMMER) and the valve (RELAP5) representing the cap in the simulations are set to open and the injection starts; the water continues to flow for about $1 \mathrm{~s}$, and then the injection is stopped by closing valve VP-SBL-06 $(\mathrm{t}=1.2 \mathrm{~s})$.

As can be seen from Figures 14 and 15, the pressurization rate of the injection line (PT-SBL-02) is well-captured for both the configurations for the whole interval; however, the two simulations differ in the prediction of the absolute values of the pressure: the standalone one shows a remarkable underprediction of about 20 bars all along the transient, whilst the coupled configuration perfectly matches the value of the experimental pressure. Compared against the experimental data, the coupled RELAP5 was also able to capture the oscillations of the pressure in the line caused by the abrupt rupture of the cap, and it also matched the damping time ( $\sim 0.4 \mathrm{~s})$. As stated above, the error in the standalone case is due to the limited capability of SIMMER in reproducing the geometry of the injection line and, consequently, the behavior of the injected water. At the end of the injection $(\sim 1.2 \mathrm{~s})$ the pressure drops sharply in the standalone configuration, while it decreases slowly-more similar to the experimental data-in the coupled configuration.

The continuous green line shown in Figures 14 and 15 represents the pressurization of the vessel S1B, as captured, during the experiment, by the pressure transducer PT-S1B-01; the dashed black line, instead, is the pressure calculated by SIMMER during the simulation. It is clear, comparing the two lines, that both the configurations correctly predict this slow increase in the pressure, with a slightly better match for the coupled codes towards the end of the transient. Indeed, the larger and most critical difference with the experimental data is seen at the very beginning of the pressurization, immediately after the rupture. In the experiment, an extremely fast and high-pressure peak was detected, but this peak was not predicted in either of the two simulations; instead, a much smaller peak is seen-almost 10-times smaller. Since both the signals (experimental and numerical) are recorded at the same frequency $\left(10^{4} \mathrm{~Hz}\right)$, this error cannot be attributed to a difference in the sampling time. This might indicate that the fast pressure peaks in the experiment could derive from the interaction of the solid material (steel components) with the liquid metal, which SIMMER cannot simulate.

Comparing the pressure, one last important observation can be drawn from the numerical work, given the final scope of the whole analysis, since the main objective is the study of the chemical interaction between $\mathrm{PbLi}$ and water. The kinetic of this reaction is still scarcely understood, and the experimental and numerical campaign of Lifus5/Mod3 I s also aimed at a better understanding the real impact of this parameter. The chemical module in SIMMER does not provide a direct control for the kinetic of the reaction, but it is possible to use a parameter which limits the amount of hydrogen produced by the reaction in each time-step, thereby effectively adjusting the velocity of the reaction. During this work, it was found that relatively high velocities of the reaction would bring about a slower pressurization and significant underpredictions of the pressure inside the S1Bs; this might sound counterintuitive, since a faster reaction should cause a faster increase of the pressure. However, the effect of the chemical reaction is to cause high pressure peaks only locally, where the reaction takes place, and especially close to the injection point, consequently slowing down the flow of the water and the pressurization of the vessel. Figure 16 provides an example of this behavior: the blue and red lines are the results of two simulations with different reaction velocities (FKCR coefficient, as explained above). The velocity of the 
reaction does not have any significant impact on the pressure in the injection line, but it strongly affects the pressure inside the S1B vessel, with the lower rate (blue line, FKCR $10^{-6}$ ) leading to a higher pressure during the whole transient. Overall, the simulation seems to suggest that the chemical reaction can be assumed relatively slow and as having a small impact on the first seconds of the transient.

\subsubsection{Temperature Evolution}

Figures 17 and 18 collect the temperature trends simulated by the standalone and coupled simulations, respectively, plotted against the experimental data. The trends are collected by ring location and level (i.e., radial and axial position); the reader can refer to Table 5 for a better understanding of the positions. It is important to notice that, as already stated above, this part of the numerical work was focused on the initial seconds of the experiment, chiefly on the transients related to the injection of the water and the pressurization of the S1B vessel, whilst it is clear from the conclusion of this work that a much longer time interval is needed to have a comprehensive evaluation of the codes for what concerns the temperatures. However, some important observations can be drawn from these results.

First of all, it is evident from the comparison with the experimental data that both the configurations of the codes predict a significantly more chaotic behavior for the transients in all the analyzed locations. Indeed, in the experiment, the temperatures at all the positions showed a relatively slow and smooth increase, which never presented significant peaks and never reached beyond $100{ }^{\circ} \mathrm{C}$ above the start temperatures; the simulation in both the configurations revealed many fast peaks, especially in the radial positions close to the injection cap, with the coupled simulations showing an interesting behavior with a regular oscillation frequency. Furthermore, it is interesting to notice that SIMMER simulations show a significant drop in the temperatures close to the injection point immediately after the cap rupture: this trend is not observed in the experimental data.

These behaviors are still under investigation, but they might be related to a balance between the evaporation (through flashing) of the water injected in the vessel and the energy released by the chemical reaction.

A certain degree of uncertainty remains regarding the choice of the temperature to be compared with experimental data, since SIMMER is able to provide the temperatures of the different liquids and the temperature of the gas, but it is not fully clear what would be the proper comparison with experimental thermocouples measuring in a multiphase environment.

However, as a general conclusion, the coupled configuration seems to provide a substantially better estimation of the evolution of the temperatures, both in terms of the quality of the transients and in terms of the absolute values. Given the difference between the two configurations, this is most likely due to an improved control of the behavior of the water in the injection line.

\subsubsection{Mass Flow Rate and Hydrogen Production}

Figures 19-21 show, respectively, the liquid water flow rate, the total amount of water injected, and the total mass of hydrogen generated inside the S1B vessel; the last two values are also compared against the estimation obtained through the experimental data.

The mass flow rate of injected water is significantly higher in the standalone simulation, with two abrupt changes shown at the instants in which the cap rupture and the closing of valve VP-SBL-06 occur. This behavior is quite unphysical, and it corroborates once again the shortcomings of SIMMER in properly simulating long pipelines and valve actions. However, the total mass of water injected during the whole transient remains inside the estimated experimental value, as shown in Figure 20. 


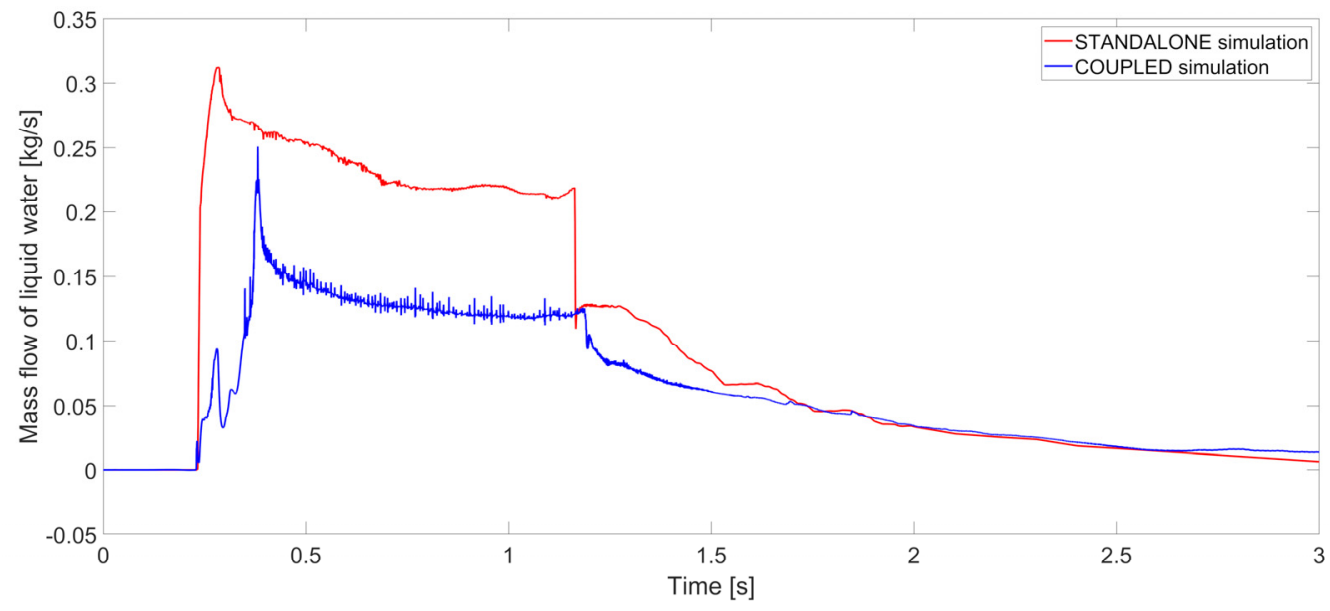

Figure 19. Standalone and Coupled simulations-liquid water mass flow rate in the injection line.

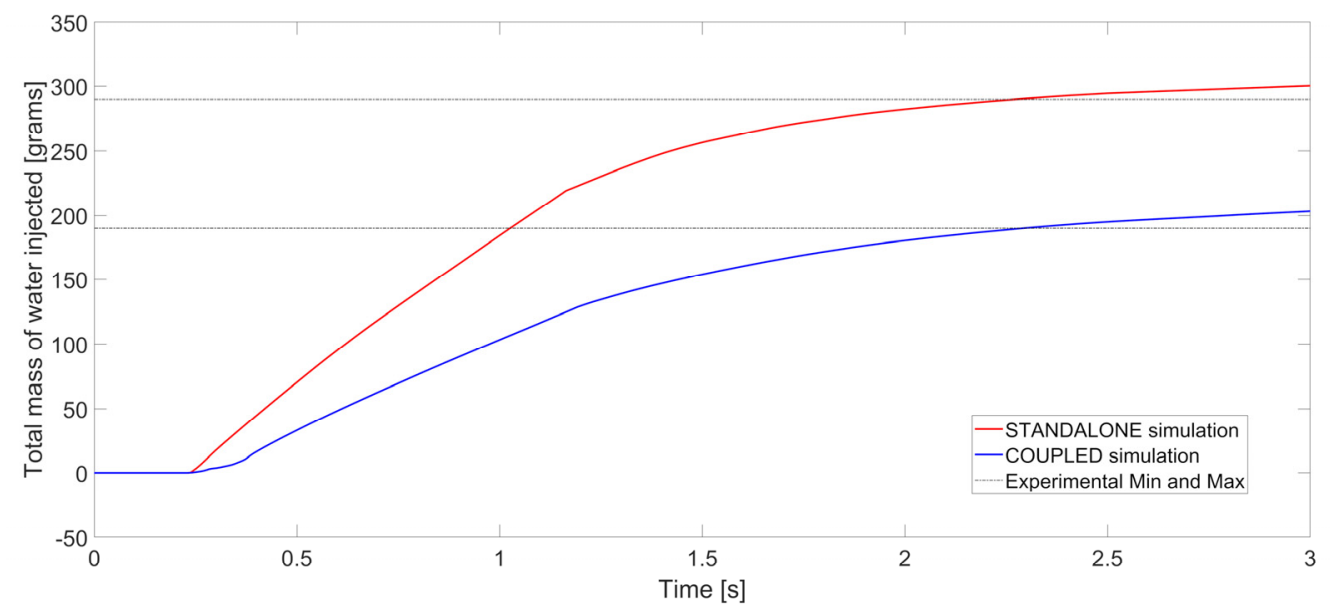

Figure 20. Standalone and Coupled simulations_-total mass of liquid water injected in S1B.

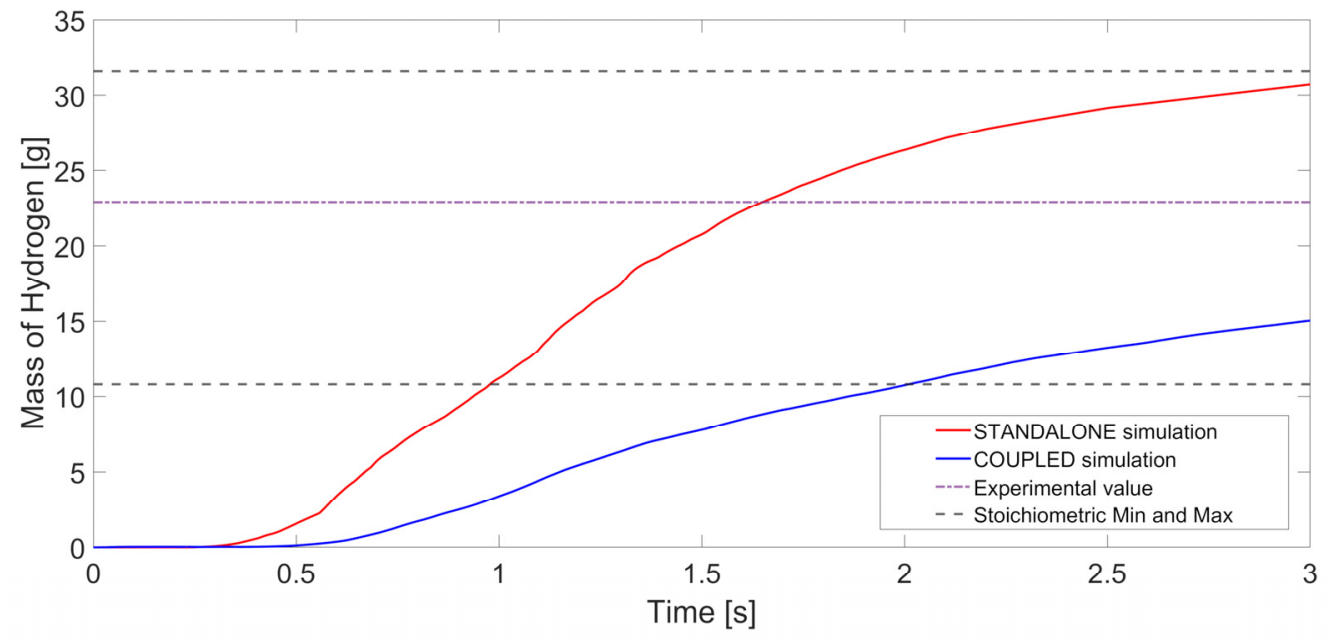

Figure 21. Standalone and Coupled simulations—-total mass of generated hydrogen.

Regarding the amount of hydrogen produced (Figure 21), the two simulations showed different results, with higher values predicted by the standalone configuration: this was, nonetheless, expected, since the final hydrogen production depends on the total mass of injected water. Furthermore, both the simulations showed that the hydrogen generation did not reach an entirely steady state value, with the chemical reaction still active after 
3 s of simulation; however, the hydrogen production seemed to nearly reach a plateau, with the final level close to the experimental one, especially for the coupled configuration. Even though this predicted time evolution is useful for supporting the necessity of further analysis with longer transients, it is important to stress that these results cannot be used to validate a specific hydrogen production rate and, consequently, provide an estimation of the kinetic of the reaction, since the experimental value was calculated a posteriori, and no experimental time trends are available concerning the hydrogen generation.

Table 7. Test E4.1, main parameters.

\begin{tabular}{|c|c|c|c|c|c|c|}
\hline \multirow[t]{2}{*}{ \# } & \multirow{2}{*}{$\begin{array}{c}\text { LIFUS5/Mod3 } \\
\text { Parameter }\end{array}$} & \multicolumn{5}{|c|}{ Test E4.1 } \\
\hline & & ID & Unit & Experiment & Standalone & Coupled \\
\hline \multicolumn{7}{|c|}{ SYSTEM S1B } \\
\hline S1-1 & P@SoT & PC-S1B-01 & bar & 0.7 & 1.00 & 1.28 \\
\hline S1-2 & $\mathrm{T}_{\mathrm{PbLi}} @ \mathrm{SoT}$ & average & ${ }^{\circ} \mathrm{C}$ & 333.9 & 337.00 & 337.00 \\
\hline S1-3 & PbLi LVL (from S1B top flange) & TC-S1B-L1/L2 & $\mathrm{mm}$ & -50 & -50 & -50 \\
\hline S1-4 & Vol. gas & - & 1 & 4.073 & 4.6 & 4.1 \\
\hline S1-5 & First $\mathrm{P}$ peak at the injector cap rupture & PT-S1B-03 & bar & 217.7 & 19.84 & 14.76 \\
\hline S1-6 & Second delayed P peak & PT-S1B-01 & bar & 74.2 & 16.04 & 9.40 \\
\hline S1-7 & $\begin{array}{l}\text { Ratio between } P_{\text {peak }} 1 \text { and } P_{\text {injection_line }} \\
\text { at the injector cap rupture }\end{array}$ & - & - & 1.49 & 0.15 & 0.11 \\
\hline S1-8 & $\begin{array}{l}\text { Ratio between } \mathrm{P}_{\text {peak }} 2 \text { and } \mathrm{P}_{\text {injection_line }} \\
\text { at the injector cap rupture }\end{array}$ & - & - & 0.51 & 0.12 & 0.07 \\
\hline S1-9 & $\mathrm{P}$ at EoT & PT-S1B-01/03 & bar & 94.0 & 44.33 & 62.43 \\
\hline S1-10 & Rupture disk open time & PC-BYP-01 & $\mathrm{s}$ & - & - & 0.00 \\
\hline S1-11 & Min $\mathrm{T}_{\mathrm{PbLi}}$ & - & ${ }^{\circ} \mathrm{C}$ & - & 508.00 & 235.00 \\
\hline S1-12 & $\operatorname{Max} \mathrm{T}_{\mathrm{PbLi}}$ & TC-R61-L3 & ${ }^{\circ} \mathrm{C}$ & 439.67 & 1210.42 & 1709.87 \\
\hline S1-13 & $\mathrm{T}_{\mathrm{PbLi}}$ at EoT (Level 6) & TC-RXY-L6 & ${ }^{\circ} \mathrm{C}$ & $345-384$ & 750.61 & 527.29 \\
\hline \multicolumn{7}{|c|}{ SYSTEM SBL } \\
\hline S2-1 & $\mathrm{P}$ in gas line at SoT & PC-SBL-02 & bar & 158.8 & 158.70 & 158.70 \\
\hline S2-2 & $\mathrm{P}$ at SoT & PC-SBL-01 & bar & 158.7 & 158.70 & 158.70 \\
\hline S2-3 & $\mathrm{T}$ at SoT & TC-SBL-04 & ${ }^{\circ} \mathrm{C}$ & 274.7 & 304.78 & 302.51 \\
\hline S2-4 & Min. P during injection & PT-SBL-01 & bar & 115.73 & 117.01 & 110.00 \\
\hline S2-5 & $\mathrm{P}$ at EoT & PC-SBL-01 & bar & 163.5 & 155.00 & 155.00 \\
\hline S2-6 & $\mathrm{T}$ at EoT & TC-SBL-01/05 & ${ }^{\circ} \mathrm{C}$ & 263.0 & 319.72 & 277.02 \\
\hline S2-7 & Mass of water injected & MT-SBL-01 & g & 194-285 & 300 & 202.08 \\
\hline \multicolumn{7}{|c|}{ INJECTION SYSTEM } \\
\hline $\mathrm{I}-1$ & Start of injection (valve opening instant) & - & $\mathrm{s}$ & 0 & 0 & 0 \\
\hline $\mathrm{I}-2$ & Injection time (from cap rupture) & - & $\mathrm{s}$ & 0.9274 & 0.92 & 0.93 \\
\hline $\mathrm{I}-3$ & Injector cap rupture instant & - & $\mathrm{s}$ & 0.2294 & 0.23 & 0.22 \\
\hline $\mathrm{I}-4$ & Pressure of cap rupture & PT-SBL-02 & bar & 146.3 & 132.03 & 134.98 \\
\hline $\mathrm{I}-5$ & Pressurization rate & PT-SBL-02 & $\mathrm{bar} / \mathrm{s}$ & 633.3 & 571.18 & 698.51 \\
\hline $\mathrm{I}-6$ & Injection valve fully closed instant & - & $\mathrm{s}$ & 1.1568 & 1.148 & 1.150 \\
\hline \multicolumn{7}{|c|}{ SYSTEM H2 } \\
\hline $\mathrm{H}-1$ & $\mathrm{H} 2$ generated & - & $\mathrm{g}$ & 22.91 & 30.73 & 15.05 \\
\hline
\end{tabular}




\section{Discussion and Conclusions}

The objective of the Test E4.1 was successfully achieved and the acquired measurements contributed to the enlargement of existing databases and the increasing of the comprehension of the phenomena occurring during $\mathrm{PbLi} /$ water interactions, as well as provided experimental data with defined initial and boundary conditions. The transient can be divided into four phases, according to the pressure trend.

The test confirmed the dynamic of the $\mathrm{PbLi}$ /water interaction, where the thermodynamic interaction is the predominant process occurring in the first hundreds of milliseconds after the cap rupture, followed by the secondary process, involving the chemical reaction, which generates hydrogen and an increase in temperature. During the injection of water into the reaction vessel S1B, the pressure sensors recorded several initial narrow peaks, lasting for a few milliseconds, due to the instantaneous flashing of the injected water, followed by the expansion of steam and gas through the perforated top plate of the test section towards the gas plenum. The maximum pressure peak, due to the flashing of water, was 217.7 bar. Moreover, the pressure data overlapped with the strain data permitted the recognition of the pressure-wave propagation and the investigation of the dynamic effects of energy release on the structures.

Concerning the temperature behavior, in test E4.1, the cooling effect due to the flashing of water and its expansion disappeared. This is due to the shape of the water jet, which was almost spread when it was injected into the melt. Moreover, the spread of the jet led to a general increase of temperature in the whole system, due to the heat generated by the chemical reaction occurring at the interface between fluids, without significant temperature peaks.

Regarding the quantification of the hydrogen, which is one of the crucial data to be used in the code validation activity, the experimental result (22.91 g) was in the foreseen range and was calculated by the stoichiometry, according to the predominant reaction between $\mathrm{PbLi}$ and water, and considering the evaluation of the injecting water (194-284 g).

Finally, the experimental results of test E4.1 permitted the obtaining of reliable data to be used for the validation of the modified-version SIMMER-III code for fusion applications, and of the coupled RELAP5/SIMMER approach.

As for the numerical viewpoint, the experimental test E4.1 was simulated using two different methodologies. In the first case, SIMMER-III was used in a standalone configuration to simulate the S1B vessel and a rough geometrical approximation of the whole injection line of the LIFUS5/Mod3 facility; in the second case, SIMMER-III was kept for the simulation of the S1B, but it was also coupled with the code RELAP5 (version 3.3), which allowed for the creation of a nodalization which was significantly closer to the real geometry of the injection line. The numerical results were then compared with the experimental data in order to provide a better understanding of the performance of the two methodologies, and a first evaluation of the capability of SIMMER-III code in simulating the transients characterizing the Series E.

The numerical results presented here show that the code SIMMER-III is capable of correctly capturing the main phenomena involved in the experiments, providing good estimations, especially for the long pressure transients in the S1B vessel. Furthermore, the coupled technique worked smoothly, and outperformed the standalone simulation, with a significantly superior prediction of the pressurization in the injection line, allowing for more flexibility on the handling of the behavior of the valves and the imposition of the boundary conditions.

Regarding the chemical reaction, and considering the final hydrogen generation, the code results seem satisfactory and coherent with the experimental results and the stoichiometric calculations; nevertheless, more work is needed to improve the quantitative prediction of the temperatures, even though the coupled technique already shows a substantial improvement. Another important conclusion for the chemical reaction is an early indication that the reaction appears to have a much stronger impact on long transients and a lesser effect at the early stages of the experiment; while further investigation is 
certainly necessary to confirm this trend, this might be an important advancement in a comprehensive definition of the kinetic of the reaction.

The achievements reached during the experimental activities performed under FP8 EUROfusion Horizon 2020 will be the starting point of the new R\&D plan in the framework of FP9 EUROfusion Horizon Europe. A new LIFUS5/Mod4 Integral Test Facility (ITF) has been designed and will be installed at ENEA CR Brasimone. The facility is a full-scale representative of the WCLL TBM PbLi loop and it will be coupled with the Water Loop facility, a full-scale representative of the WCLL TBM Water Cooling System. The objective of the experimental campaign is to investigate the phenomenology, the behavior, and the response of the WCLL Test Blanket Systems under in-box LOCA at integral levels and in relevant operative conditions. Moreover, the facility will be able to reproduce and assess the effectiveness of the safety functions and procedures implemented in such scenarios. This involves continuing the validation activity on the code-coupling and the procedure for its application, together with the validation of SIMMER against ITF experiments.

Author Contributions: Conceptualization, M.E. and A.D.N., methodology, M.E. and F.G.; software, M.E. and F.G.; validation, F.G. and M.E.; investigation, M.E., F.G. and N.B.; data curation, M.E. and F.G.; formal analysis, M.E. and F.G.; writing-original draft preparation, M.E., F.G. and N.B.; writing-review and editing, M.E.; supervision, A.D.N., N.F. and A.C. All authors have read and agreed to the published version of the manuscript.

Funding: This work has been carried out within the framework of the EUROfusion Consortium and has received funding from the Euratom research and training programmes 2014-2018 and 2019-2020, under grant agreement No 633053. The views and opinions expressed herein do not necessarily reflect those of the European Commission.

Institutional Review Board Statement: Not applicable.

Informed Consent Statement: Not applicable.

Data Availability Statement: Data sharing is not applicable to this article.

Conflicts of Interest: The authors declare no conflict of interest. The funders had no role in the design of the study; in the collection, analyses, or interpretation of data; in the writing of the manuscript, or in the decision to publish the results.

\section{References}

1. Del Nevo, A.; Arena, P.; Caruso, G.; Chiovaro, P.; Di Maio, P.; Eboli, M.; Edemetti, F.; Forgione, N.; Forte, R.; Froio, A.; et al. Recent progress in developing a feasible and integrated conceptual design of the WCLL BB in EUROfusion project. Fusion Eng. Des. 2019, 146, 1805-1809. [CrossRef]

2. Martelli, E.; Del Nevo, A.; Arena, P.; Bongiovì, G.; Caruso, G.; Di Maio, P.A.; Eboli, M.; Mariano, G.; Marinari, R.; Moro, F.; et al. Advancements in DEMO WCLL breeding blanket design and integration. Int. J. Energy Res. 2017, 42, 27-52. [CrossRef]

3. Del Nevo, A.; Martelli, E.; Agostini, P.; Arena, P.; Bongiovì, G.; Caruso, G.; Di Gironimo, G.; Di Maio, P.; Eboli, M.; Giammusso, R.; et al. WCLL breeding blanket design and integration for DEMO 2015: Status and perspectives. Fusion Eng. Des. 2017, 124, 682-686. [CrossRef]

4. Tassone, A.; Del Nevo, A.; Arena, P.; Bongiovi, G.; Caruso, G.; Di Maio, P.A.; Di Gironimo, G.; Eboli, M.; Forgione, N.; Forte, R.; et al. Recent Progress in the WCLL Breeding Blanket Design for the DEMO Fusion Reactor. IEEE Trans. Plasma Sci. 2018, 46, 1446-1457. [CrossRef]

5. Cismondi, F.; Spagnuolo, G.; Boccaccini, L.; Chiovaro, P.; Ciattaglia, S.; Cristescu, I.; Day, C.; Del Nevo, A.; Di Maio, P.; Federici, G.; et al. Progress of the conceptual design of the European DEMO breeding blanket, tritium extraction and coolant purification systems. Fusion Eng. Des. 2020, 157, 111640. [CrossRef]

6. Eboli, M.; Forgione, N.; Del Nevo, A. Implementation of the chemical PbLi/water reaction in the SIMMER code. Fusion Eng. Des. 2016, 109-111, 468-473. [CrossRef]

7. Eboli, M.; Forgione, N.; Del Nevo, A. Assessment of SIMMER-III code in predicting Water Cooled Lithium Lead Breeding Blanket "in-box-Loss of Coolant Accident". Fusion Eng. Des. 2020, 163, 112127. [CrossRef]

8. D'Auria, F.; Galassi, G.M. Code Assessment Methodology and Results; IAEA Technical Workshop/Committee on Computer Aided Safety Analyses: Moscow, Russia, 1990.

9. Bonuccelli, M.; D'Auria, F.; Debrecin, N.; Galassi, G.M. A Methodology for the Qualification of Thermalhydraulic Code Nodalizations. In Proceedings of the NURETH-6 Conference, Grenoble, France, 5-8 October 1993. 
10. Eboli, M.; Del Nevo, A.; Pesetti, A.; Forgione, N.; Sardain, P. Simulation study of pressure trends in the case of loss of coolant accident in Water Cooled Lithium Lead blanket module. Fusion Eng. Des. 2015, 98-99, 1763-1766. [CrossRef]

11. Eboli, M.; Del Nevo, A.; Forgione, N.; Porfiri, M.T. Post-test analyses of LIFUS5 Test\#3 experiment. Fusion Eng. Des. 2017, 124, 856-860. [CrossRef]

12. Eboli, M.; Moghanaki, S.K.; Martelli, D.; Forgione, N.; Porfiri, M.T.; Del Nevo, A. Experimental activities for in-box LOCA of WCLL BB in LIFUS5/Mod3 facility. Fusion Eng. Des. 2019, 146, 914-919. [CrossRef]

13. Eboli, M.; Crugnola, R.M.; Cammi, A.; Khani, S.; Forgione, N.; Del Nevo, A. Test Series D experimental results for SIMMER code validation of WCLL BB in-box LOCA in LIFUS5/Mod3 facility. Fusion Eng. Des. 2020, 156, 111582. [CrossRef]

14. Moghanaki, S.K.; Eboli, M.; Forgione, N.; Martelli, D.; Del Nevo, A. Validation of SIMMER-III code for in-box LOCA of WCLL BB: Pre-test numerical analysis of Test D1.1 in LIFUS5/Mod3 facility. Fusion Eng. Des. 2019, 146, 978-982. [CrossRef]

15. Moghanaki, S.K.; Galleni, F.; Eboli, M.; Del Nevo, A.; Paci, S.; Forgione, N. Analysis of Test D1.1 of the LIFUS5/Mod3 facility for In-box LOCA in WCLL-BB. Fusion Eng. Des. 2020, 160, 111832. [CrossRef]

16. Moghanaki, S.K.; Galleni, F.; Eboli, M.; Del Nevo, A.; Paci, S.; Forgione, N. Post-test analysis of Series D experiments in LIFUS5/Mod3 facility for SIMMER code validation of WCLL-BB In-box LOCA. Fusion Eng. Des. 2021, 165, 112268. [CrossRef]

17. Gonfiotti, B.; Moghanaki, S.K.; Eboli, M.; Barone, G.; Del Nevo, A.; Martelli, D. Development of a SIMMER-III/RELAP5 coupling tool. Fusion Eng. Des. 2019, 146 Pt B, 1993-1997. [CrossRef]

18. Galleni, F.; Moghanaki, S.; Eboli, M.; Del Nevo, A.; Paci, S.; Ciolini, R.; Frano, R.L.; Forgione, N. RELAP5/SIMMER-III code coupling development for PbLi-water interaction. Fusion Eng. Des. 2020, 153, 111504. [CrossRef]

19. Galleni, F.; Moscardini, M.; Eboli, M.; Del Nevo, A.; Martelli, D.; Forgione, N. Preliminary analysis of an in-box LOCA in the breeding unit of the WCLL TBM for the ITER reactor with SIMMER-IV code. Fusion Eng. Des. 2021, 169, 112472. [CrossRef]

20. Moscardini, M.; Galleni, F.; Pucciarelli, A.; Eboli, M.; Del Nevo, A.; Paci, S.; Forgione, N. Thermo-hydraulic analysis of PbLi ancillary system of WCLL TBM undergoing in-box LOCA. Fusion Eng. Des. 2021, 168, 112614. [CrossRef]

21. Pucciarelli, A.; Toti, A.; Castelliti, D.; Belloni, F.; Van Tichelen, K.; Moscardini, M.; Galleni, F.; Forgione, N. Coupled system thermal Hydraulics/CFD models: General guidelines and applications to heavy liquid metals. Ann. Nucl. Energy 2020, 153, 107990. [CrossRef]

22. Eboli, M.; Del Nevo, A.; Forgione, N.; Giannetti, F.; Mazzi, D.; Ramacciotti, M. Experimental Characterization of Leak Detection Systems in HLM Pool Using LIFUS5/Mod3 Facility. Nucl. Technol. 2020, 206, 1409-1420. [CrossRef]

23. Pesetti, A.; Del Nevo, A.; Forgione, N. Experimental investigation and SIMMER-III code modelling of LBE-water interaction in LIFUS5/Mod2 facility. Nucl. Eng. Des. 2015, 290, 119-126. [CrossRef]

24. PED Directive. Available online: https://ec.europa.eu/growth/sectors/pressure-equipment-and-gas-appliances/pressureequipment-sector/pressure-equipment_en (accessed on 27 October 2021).

25. AA.VV. SIMMER-III (Version3.F) Input Manual; O-arai Engineering Center, Japan Nuclear Cycle Development Institute: Ibaraki, Japan, May 2012.

26. AA.VV. SIMMER-IV (Version 3.F) Input Manual; O-arai Engineering Center, Japan Nuclear Cycle Development Institute: Ibaraki, Japan, May 2012.

27. Green Rot Effects. Available online: https://blog.wika.us/products/temperature-products/green-rot-affects-type-kthermocouples/ (accessed on 27 October 2021). 